\title{
A Darwinian Perspective on "Exchange Rate Undervaluation"
}

\author{
Qingyuan Du and Shang-Jin Wei*
}

Dec 26, 2015

\begin{abstract}
This paper studies how status competition for marriage partners can generate surprising effects on the real exchange rate (RER). In theory, a rise in the sex ratio (increasing relative surplus of men) can generate a decline in the RER. The effect can be quantitatively large if the biological desire for a marriage partner is strong. We also provide within-China and cross-country empirical evidence to support the theory. As an application, our cross-country estimation suggests that sex ratio as well as other factors in the existing literature can account for the recent evolution in Chinese RER almost completely.
\end{abstract}

Key words: surplus men, equilibrium real exchange rate, currency manipulation JEL code: F3, F4, J1 and J7

\footnotetext{
*Qingyuan Du: Monash University, Department of Economics, Building H.4.49, 900 Dandenong Road, Caulfield East, VIC, Australia, 3145 (email: qingyuan.du@monash.edu); Shang-Jin Wei (corresponding author): Asian Development Bank, 6 ADB Avenue, 1550 Metro Manila, Philippines. swei@adb.org. This is a revised version of NBER Working Paper \# 16788, originally released in 2011. This research is supported by the US National Science Foundation grant SES-1024574 and Faculty Research Grant 1755616, Faculty of Business and Economics, Monash University, which we gratefully acknowledge. We thank Zhi Wang for some of the data, and Jeff Frankel, Takatoshi Ito, Francis Lui, Andrew Rose, Xiaobo Zhang, and conference/seminar participants at the NBER, UC Berkeley, UC Davis, Columbia University, the International Monetary Fund, Federal Reserve Bank of San Francisco, the World Bank, the Bank for International Settlement, the Reserve Bank of Australia, and University of Zurich for helpful comments and Joy Glazener for editorial help. We are solely responsible for any possible errors in the paper.
} 


\section{Introduction}

The real exchange rate (RER) is one of the most important relative prices for most economies. It is also often a source of international tension - witness the intense controversy over the Chinese or German exchange rate policy. Yet, our understanding of its determinants is still incomplete. This paper proposes a Darwinian determinant of the real exchange rate, which we argue should play an important (but still neglected) role in understanding some of the major exchange rate patterns.

For concreteness, let us reflect more on the international controversy about the Chinese exchange rate, although the mechanism proposed in the paper should be relevant for many other economies that share some common features with China. The Chinese real exchange rate was widely believed to be substantially undervalued in the first decade of the 21 st century. Relative to the purchasing power parity (PPP), the exchange rate appeared to be undervalued by $40 \%$ or more. The standard narrative attributes this pattern to government interventions in the currency market.

However, this narrative is only correct if one has already taken into account all the important structural determinants of the real exchange rate. In this paper, we investigate one such determinant that is missing from the standard approach to assess the equilibrium exchange rate. In the alternative narrative, the appearance of the real exchange rate undervaluation is an outcome of an imbalance in the sex ratio in the pre-marital age cohort that began around 2003 and has become progressively worse since then. The Chinese exchange rate policy only became a source of international tension since 2003, and we will argue that the timing is not coincidental.

The sex ratio imbalance itself starts from some technology and policy shocks, unrelated to the nominal exchange rate policy. The initial technology shock in the new narrative was the spread of ultrasound B machines in China since the 1980s that allowed expectant parents to easily detect the gender of the fetus and abort the child they did not want. 1985 was the first year in which half of the local (county level) hospitals acquired at least one such machine (Li and Zheng, 2009). The initial policy shock was the implementation of a strict version of the family planning policy (popularly known as the "one-child policy") that severely restricts the number of children a couple can have. By interacting with a long-existing parental preference for sons, the combination of the two shocks started to produce an unnaturally high ratio of boys to girls at birth from the early 1980s, and the sex ratio at birth became progressively worse as the use of ultrasound machines became more widespread, and the enforcement of the family planning policy tightened over time. Around 2003, the first cohort born with an excess number of males was entering the marriage market. The competition for a marriage partner by young men became progressively more fierce since then. In 2007, the sex ratio for the pre-marital age cohort (5-20) was about 115 young men per 100 young women. This implies that about one out of every nine young men 
cannot get married, mathematically speaking.

Our theory predicts that a rise in the sex ratio in the pre-marital age cohort can lead to an appearance of an undervalued exchange rate relative to the PPP. This happens through both a savings channel and a labor supply channel.

How would a rise in the sex ratio imbalance trigger a significant increase in the savings rate starting from about 2003? The key is to recognize that family wealth is an important status variable in the marriage market (other things equal). As the competition for brides intensifies, young men and their parents raise their savings rate in order to improve their relative standing in the marriage market. (Of course, any complete story has to investigate why the behavior by women or their parents does not undo the competitive savings story. This we will do in the model. In addition, we will argue that the corporate savings will also go up in response to a higher sex ratio.)

When the economy-wide savings rate rises, the real exchange rate often falls. To see this, we recognize that a rise in the savings rate implies a reduction in the demand for both tradable and non-tradable goods. Since the price of the tradable goods is tied down by the world market, this translates into a reduction in the relative price of the non-tradable goods, and hence a decline in the value of the real exchange rate (a departure from the PPP). The effect would be persistent if there are frictions that impede the reallocation of factors between the tradable and non-tradable sectors. The savings channel can be economically and quantitatively significant if the biological desire for a marriage partner is sufficiently strong.

The second channel for the sex ratio imbalance to affect the real exchange rate works through the effective labor supply. A rise in the sex ratio can also motivate men to cut down leisure and increase labor supply. This leads to an increase in the economy-wide effective labor supply. If the non-tradable sector is more labor intensive than the tradable sector, this generates a Rybczynski-like effect, leading to an expansion of the non-tradable sector at the expense of the tradable sector. The increase in the supply of non-tradable goods leads to an additional decline in the relative price of non-tradables and a further decline in the value of the RER. Again, the labor supply channel can be economically powerful if the biological desire to avoid involuntary bachelorhood is strong.

Putting the two channels together, a rise in the sex ratio generates a real exchange rate that appears too low relative to the purchasing power parity (or relative to the standard approach used by the IMF to assess equilibrium exchange rates that includes additional terms beyond PPP but does not include the sex ratio, savings rate, and effective labor supply). Because the effect of a skewed sex ratio on the real exchange rate comes from competition for sex partners, this is fundamentally a Darwinian perspective on the exchange rate.

Of course, other structural factors may also have contributed to an increase in the 
aggregate savings rate (e.g., an increase in government savings or an increase in privatesector precautionary savings) or an increase in the effective labor supply (e.g., gradual relaxation of restrictions on rural-urban migration). These other factors would reinforce the Darwinian mechanism discussed in this paper, causing the real exchange rate to fall further.

A desire to enhance one's prospects in the marriage market through a higher level of wealth could be a motive for savings or labor supply even in countries with a balanced sex ratio. But such a motive is not as easy to detect when the competition is modest. When the sex ratio gets out of balance, obtaining a marriage partner becomes much less assured. A host of behaviors that are motivated by a desire to succeed in the marriage market may become magnified. But sex ratio imbalances so far have not been investigated by macroeconomists. This may be a serious omission.

A sex ratio imbalance is a common demographic feature in many economies, especially in East, South, and Southeast Asia, such as Korea, India, Vietnam, Singapore, Taiwan, and Hong Kong, in addition to China. It is quite possible that the sex ratio effect plays an important role in the real exchange rate of these economies. To be clear, most countries in the world do not have a severe sex ratio imbalance. Correspondingly, there are not enough variations in the sex ratio among these countries to detect its role in determining the level of the exchange rate. However, if one only considers the standard determinants of the real exchange rate and ignores the sex ratio effect, one could mistakenly conclude that countries with a severe sex ratio imbalance have a severely undervalued currency. This set of countries happens to include China - the world's second largest economy and the largest exporter. Given the enormous effort by international financial institutions and many national governments to pass judgment on its exchange rate, getting it right has global importance.

The empirical evidence on the savings channel is provided by Wei and Zhang (2011a). First, across rural households with a son, they document that the savings rate tends to be higher in regions with a higher sex ratio imbalance (holding constant family income, age, gender, educational level of the household head, and other household characteristics). In comparison, for rural households with a daughter, their savings rate appears to be uncorrelated with the local sex ratio. Across cities, both households with a son and households with a daughter tend to have a higher savings rate in regions with a more skewed sex ratio, although the elasticity of the savings rate with respect to the sex ratio tends to be bigger for son families. Second, across Chinese provinces, they find a strong positive correlation between the local savings rate and the local sex ratio, after controlling for the age structure of the local population, income level, inequality, recent growth rate, local birth rate, local enrollment rate in the social safety net, and other factors. Third, to go from correlation to causality, they explore regional variations in the enforcement of the family planning policy as instruments for the local sex ratio, and confirm the findings in the OLS regressions. The 
sex ratio effect is both economically and statistically significant. While the Chinese household savings rate approximately doubled from 16\% (of disposable income) in 1990 to $31 \%$ in 2007, Wei and Zhang (2011a) estimate that the rise in the sex ratio could explain about half the increase in the household savings rate.

Besides the paper cited above, there are four bodies of work that are related to the current paper. First, the theoretical and empirical literature on the real exchange rate is too voluminous to summarize comprehensively here. Sarno and Taylor (2002) and Chinn (2012) provide recent surveys. Second, the literature on status goods, positional goods, and social norms (e.g., Cole, Mailath, and Postlewaite, 1992; Corneo and Jeanne, 1999; Hopkins and Kornienko, 2004; and Hopkins, 2009) has offered many useful insights. One key point is that when wealth can improve one's social status (including improving one's standing in the marriage market), in addition to affording a greater amount of consumption goods, there is an extra incentive to save. This element is in our model as well. However, all existing theories on status goods feature a balanced sex ratio. Yet, an unbalanced sex ratio presents some non-trivial challenges. In particular, while a rise in the sex ratio is an unfavorable shock to men, it is a favorable shock to women. Could the women strategically reduce their savings so as to completely offset whatever increments in savings men may have? In other words, the impact on aggregate savings from a rise in the sex ratio appears ambiguous. Our model will address this question. In any case, the literature on status goods has no discernible impact in macroeconomic policy circles. For example, while there are voluminous documents produced by the International Monetary Fund or speeches by US officials on China's high savings rate, no single paper or speech thus far has pointed to a possible connection with its high sex ratio imbalance.

A third related literature is the economics of family, which is also too vast to be summarized here comprehensively. One interesting insight from this literature is that a married couple's consumption has a partial public goods feature (Browning, Bourguignon, and Chiappori, 1994; Donni, 2006). We make use of this feature in our model as well. An insightful paper by Bhaskar and Hopkins (2011) studies parental investment in their children before they go to the marriage market. When there is a surplus of boys, parents overinvest in boys and underinvest in girls but the total investment in children is excessive. Du and Wei (2013) examine the effect of higher sex ratios for aggregate savings and current account balances. None of the papers in this literature explores the general equilibrium implications for exchange rates from a change in the sex ratio.

The fourth literature examines empirically the causes of a rise in the sex ratio. The key insight is that the proximate cause for the recent rise in the sex ratio imbalance is sexselective abortions, which have been made increasingly possible by the spread of Ultrasound $\mathrm{B}$ machines. There are two deeper causes for the parental willingness to disproportionately abort female fetuses. The first is the parental preference for sons, which in part has to 
do with the relatively inferior economic status of women. When the economic status of women improves, sex-selective abortions appear to decline (Qian, 2008). The second is either something that leads parents to voluntarily have a lower fertility rate than earlier generations, or a government policy that limits the number of children a couple can have. In regions of China where the family planning policy is less strictly enforced, there is also less sex ratio imbalance (Wei and Zhang, 2011a). Bhaskar (2011) examines parental sex selections and their welfare consequences.

The rest of the paper is organized as follows. In Section 2, we construct a simple overlapping generations (OLG) model with only one gender, and show that structural shocks can produce a real exchange rate depreciation. In Section 3, we present an OLG model with two genders, and demonstrate that a rise in the sex ratio could lead to a fall in the value of the real exchange rate. In Section 4, we calibrate the model to see if and when the sex ratio imbalance can produce changes in the real exchange rate whose magnitude is economically significant. In Section 5, we provide some empirical evidence on the connection between the sex ratio and the real exchange rate. Section 6 offers concluding remarks and discusses possible future research.

\section{A benchmark model with one gender}

We start with a simple benchmark model with one gender. This allows us to see both the savings channel and the labor supply channel in a transparent way. The setup is standard, and the discussion will pave the way for a model in the next section that features two genders and an unbalanced sex ratio.

\subsection{Consumers}

There are two types of agents: consumers and producers. Consumers live for two periods: young and old. In the first period (young), a representative consumer supplies labor in exchange for labor income, consumes a part of the income and saves the rest. In the second period (old), she does not work and consumes her savings with interest.

The final good $C_{t}$ consumed by the representative consumer consists of two parts: a tradable good $C_{T t}$ and a non-tradable good $C_{N t}$.

$$
C_{t}=\frac{C_{N t}^{\gamma} C_{T t}^{1-\gamma}}{\gamma^{\gamma}(1-\gamma)^{1-\gamma}}
$$

We normalize the price of the tradable good to be one, and let $P_{N t}$ denote the relative price of the non-tradable good. The consumer price index is $P_{t}=P_{N t}^{\gamma}$. 
The optimization problem for the representative consumer is

$$
\max u\left(C_{1 t}\right)+\beta u\left(C_{2, t+1}\right)
$$

with the intertemporal budget constraint

$$
P_{t} C_{1 t}=\left(1-s_{t}\right) w_{t} \text { and } P_{t+1} C_{2, t+1}=R s_{t} w_{t}
$$

where $w_{t}$ is the wage rate. We assume that everyone supplies one unit of labor inelastically. Then $w_{t}$ is also the total first period income for a young consumer. $s_{t}$ is the savings rate of the young cohort. $R$ is the gross interest rate in units of the tradable good.

The optimal conditions is

$$
\frac{u_{1 t}^{\prime}}{P_{t}}=\beta R \frac{u_{2, t+1}^{\prime}}{P_{t+1}}
$$

We start with the case of a small open economy, and assume that the law of one price for the tradable good holds. The price of the tradable good is determined by the world market, and is set to be one in each period. The interest rate $R$ in units of the tradable good is also a constant. For simplicity, we assume $\beta R=1$.

\subsection{Producers}

There are two sectors in the economy: a tradable good sector and a non-tradable good sector. Both markets are perfectly competitive. For simplicity, we make the same assumption as in Obstfeld and Rogoff (1996) that only the tradable good can be transformed into capital used in production. ${ }^{1}$

\subsubsection{Tradable good producers}

For simplicity, we assume a complete depreciation of capital at the end of every period. Tradable producers maximize

$$
\max E_{t} \sum_{\tau=0}^{\infty}(R)^{-\tau}\left[Q_{T, t+\tau}-w_{t+\tau} L_{T, t+\tau}-K_{T, t+\tau+1}\right]
$$

where the production function is

$$
Q_{T t}=\frac{A_{T t} K_{T t}^{\alpha_{T}} L_{T t}^{1-\alpha_{T}}}{\alpha_{T}^{\alpha_{T}}\left(1-\alpha_{T}\right)^{1-\alpha_{T}}}
$$

\footnotetext{
${ }^{1}$ Relaxing this assumption will not change any of our results qualitatively.
} 
Without any unanticipated shocks, the factor demand functions are, respectively,

$$
\begin{aligned}
R & =\frac{1}{\alpha_{T}^{\alpha_{T}}\left(1-\alpha_{T}\right)^{1-\alpha_{T}}} \alpha_{T} A_{T t}\left(\frac{L_{T t}}{K_{T t}}\right)^{1-\alpha_{T}} \\
w_{t} & =\frac{1}{\alpha_{T}^{\alpha_{T}}\left(1-\alpha_{T}\right)^{1-\alpha_{T}}}\left(1-\alpha_{T}\right) A_{T t}\left(\frac{K_{T t}}{L_{T t}}\right)^{\alpha_{T}}
\end{aligned}
$$

It is useful to note that when there is an unanticipated shock in period $t,(2.2)$ does not hold since $K_{T t}$ is a predetermined variable.

\subsubsection{Non-tradable good producers}

Non-tradable good producers maximize the following objective function:

$$
\max E_{t} \sum_{\tau=0}^{\infty}(R)^{-\tau}\left[P_{N, t+\tau} Q_{N, t+\tau}-w_{t+\tau} L_{N, t+\tau}-K_{N, t+\tau+1}\right]
$$

with the production function given by

$$
Q_{N t}=\frac{A_{N t} K_{N t}^{\alpha_{N}} L_{N t}^{1-\alpha_{N}}}{\alpha_{N}^{\alpha_{N}}\left(1-\alpha_{N}\right)^{1-\alpha_{N}}}
$$

Without unanticipated shocks, we have

$$
\begin{aligned}
R & =\frac{1}{\alpha_{N}^{\alpha_{N}}\left(1-\alpha_{N}\right)^{1-\alpha_{N}}} P_{N t} \alpha_{N} A_{N t}\left(\frac{L_{N t}}{K_{N t}}\right)^{1-\alpha_{N}} \\
w_{t} & =\frac{1}{\alpha_{N}^{\alpha_{N}}\left(1-\alpha_{N}\right)^{1-\alpha_{N}}} P_{N t}\left(1-\alpha_{N}\right) A_{N t}\left(\frac{K_{N t}}{L_{N t}}\right)^{\alpha_{N}}
\end{aligned}
$$

If there is an unanticipated shock in period $t,(2.4)$ does not hold.

In equilibrium, the market clearing condition for the non-tradable good pins down the price of the non-tradable good,

$$
Q_{N t}=\frac{\gamma P_{t}\left(C_{2 t}+C_{1 t}\right)}{P_{N t}}
$$

Let $x$ denote the total number of young people in the economy, then the labor market clearing condition is given by

$$
L_{T t}+L_{N t}=x
$$

Definition 1 An equilibrium in the small open economy is a set $\left\{s_{t}, K_{T, t+1}, K_{N, t+1}, L_{T t}, L_{N t}, P_{N t}\right\}$ that satisfies the following conditions: 
(i) The households' savings rates, $s_{t}=\left\{s_{i t}, s_{-i, t}\right\}$, maximize the household's welfare

$$
s_{t}=\arg \max \left\{V_{t} \mid s_{-i, t}, K_{T t+1}, K_{N t+t}, L_{T t}, L_{N t}, P_{N t}\right\}
$$

(ii) The allocations of capital stock and labor, and the output of the non-tradable good clear the factor and the output markets, and maximize the firms' profit. In other words, $\left\{K_{T, t+1}, K_{N, t+1}, L_{T t}, L_{N t}, P_{N t}\right\}$ solves (2.2), (2.3), (2.4), (2.5), (2.6) and (2.7).

\subsection{From the savings rate or labor supply to the exchange rate}

To discuss the savings channel, we consider an unanticipated increase in the discount factor $\beta$ that makes the young cohort more patient. To discuss the labor supply channel, we consider an unanticipated increase in the number of young people $L$ that enlarges the labor supply in the economy. As a result of either of these shocks, in period $t,(2.3)$ and (2.5) hold, but (2.2) and (2.4) fail.

The market clearing condition for the non-tradable good can be re-written as

$$
\frac{P_{N t} A_{N t} K_{N t}^{\alpha_{N}} L_{N t}^{1-\alpha_{N}}}{\alpha_{N}^{\alpha_{N}}\left(1-\alpha_{N}\right)^{1-\alpha_{N}}}=\gamma\left(R s_{t-1}^{\text {young }} w_{t-1}+\left(1-s_{t}^{\text {young }}\right) w_{t}\right)
$$

We can solve (2.1), (2.5), (2.3) and (2.6) to obtain the equilibrium in period $t$. To simplify, we assume that the per period utility function is of the $\log$ form, i.e., $u(C)=\ln (C)$. Following Obstfeld and Rogoff (1996) and assuming that the non-tradable good sector is relatively more labor-intensive, i.e., $\alpha_{N}<\alpha_{T}$, we can obtain the following proposition.

Proposition 1 (i) With an increase in the discount factor $\beta$ of the young cohort, the young raises their savings rate, and the price of the non-tradable good falls. As a result, the real exchange rate depreciates.

(ii) With an increase in the total number of young people $x$, the price of the non-tradable good falls. As a result, the real exchange rate depreciates.

Proof. See Appendix A.

While a formal proof is relegated to Appendix A, we provide some intuition here. In the period in which the shock to the discount factor occurs, as a representative consumer becomes more patient, he would save more and consume less. The reduction in aggregate consumption implies a reduction in the demand for both tradable and non-tradable goods. As the price of the tradable good is tied down by the world market, this leads to a decrease in the relative price of the non-tradable good (and a depreciation of the real exchange rate).

Now consider the intuition behind the labor supply channel. Under the assumption that the non-tradable sector is more labor intensive than the tradable sector, an increase in 
the number of labor generates a Rybczynski-like effect, leading to an expansion of the nontradable sector relative to the tradable sector. The increase in the supply of non-tradable goods puts downward pressure on the relative price of non-tradables and produces a decline in the value of the RER.

In summary, without currency manipulations, real factors that lead to a rise in either a country's savings rate or its labor supply can simultaneously produce a fall in the real exchange rate.

Note that the effect on the RER lasts for one period. In period $t+1$, since the shock has been observed and taken into account by consumers and firms, (2.2) and (2.4) hold in equilibrium. By solving (2.2), (2.3), (2.4) and (2.5), we have

$$
P_{N t}=R^{\frac{\alpha_{N}-\alpha_{T}}{1-\alpha_{T}}} \text { and } P_{t+1}=R^{\frac{\gamma\left(\alpha_{N}-\alpha_{T}\right)}{1-\alpha_{T}}}
$$

In other words, the price of the non-tradable good and the consumer price index go back to their initial levels. Later in the paper, we will demonstrate how frictions in the factor market can produce longer-lasting effects on the real exchange rate.

\section{A Model with Mating Competition}

We now consider a model with two genders and a desire for marriage (or for sexual partnership). Within each cohort, there are both men and women. A marriage can take place at the beginning of a cohort's second period, but only between a man and a woman in the same cohort. Once married, the husband and wife pool their first-period savings together and consume an identical amount in the second period. The second period consumption within a marriage has a partial public good feature. In other words, the husband and wife can each consume more than half of their combined second period income. Everyone is endowed with an ability to give his/her spouse some additional emotional utility (or "love"). This emotional utility is a random variable in the first period with a common and known distribution across all members of the same sex, and its value is realized and becomes public information when an individual enters the marriage market. There are no divorces.

Each generation is characterized by an exogenous ratio of men to women $\phi(\geq 1)$. All men are identical ex ante, and all women are identical ex ante. Men and women are symmetric in all aspects - in particular, men do not have an intrinsic tendency to save more or to work more - except that the sex ratio may be unbalanced.

Throughout the model, we maintain the assumption of an exogenous sex ratio. While it is surely endogenous in the long run as parental preference should evolve, the assumption of an exogenous sex ratio can be defended on two grounds. First, the technology that enables the rapid rise in the sex ratio has only become inexpensive and widely accessible 
in developing countries within the last 25 years or so. As a result, it is reasonable to think that the rising sex ratio has a major effect only on the relatively young cohort's savings decisions, but not those who have passed half of their working careers. Second, in terms of cross country experience, most countries with a skewed sex ratio have not shown a sign of reversal. This suggests that, if the sex ratio follows a mean reversion process, the speed of reversion is likely to be very slow.

\subsection{A small open economy}

For ease of discussion, we start with a small open economy with an exogenous labor supply. As in the benchmark model, the price of the tradable good is always one and the interest rate in units of the tradable good is a constant $R$.

\section{A Representative Woman's Optimization Problem}

A representative woman makes her consumption/saving decisions in her first period, taking into account the choices by men and all other women, and the likelihood that she will be married. If she fails to get married, her second-period consumption is given by $P_{t+1} C_{2, t+1}^{w, n}=$ $R s_{t}^{w} y_{t}^{w}$, where $R, y_{t}^{w}$ and $s_{t}^{w}$ are the gross interest rate of an international bond, her first period income, and her savings rate, respectively, all in units of the tradable good. If she is married, her second-period consumption is given by $P_{t+1} C_{2, t+1}^{w}=\kappa\left(R s_{t}^{w} y_{t}^{w}+R s_{t}^{m} y_{t}^{m}\right)$, where $y_{t}^{m}$ and $s_{t}^{m}$ are her husband's first period endowment and savings rate, respectively. $\kappa\left(\frac{1}{2} \leq \kappa \leq 1\right)$ represents the notion that consumption within a marriage is a public good with congestion. As an example, if two spouses buy a car, both can use it. In contrast, were they single, they would have to buy two cars. When $\kappa=\frac{1}{2}$, the husband and the wife only consume private goods. When $\kappa=1$, then all the consumption is a public good with no congestion. ${ }^{2}$

We allow each person to endogenously choose the first period labor supply, with the first period utility function given by $u(C)+v(1-L)$, where $L$ is the labor supply and $v(1-L)$ the utility from leisure. Again, for simplicity, we assume no taxes on the labor income. The utility function governing the leisure-labor choice is the same for men and women. In other words, by assumption, men and women are intrinsically symmetric except for their ratio in the society.

We can rewrite the optimization problem for a representative woman as follows:

$$
\max u\left(C_{1 t}^{w}\right)+v\left(1-L_{t}^{w}\right)+\beta E_{t}\left[u\left(C_{2, t+1}^{w}\right)+\eta^{m}\right]
$$

\footnotetext{
${ }^{2}$ By assuming the same $\kappa$ for the wife and the husband, we abstract from a discussion of bargaining within a household. In an extension later in the paper, we allow $\kappa$ to be gender specifc, and to be a function of both the sex ratio and the relative wealth levels of the two spouses, along the lines of Chiappori (1988 and 1992) and Browning and Chiappori (1998). This tends to make the response of the aggregate savings stronger to a given rise in the sex ratio.
} 
with the budget constraint

$$
\begin{aligned}
P_{t} C_{1 t}^{w} & =\left(1-s_{t}^{w}\right) w_{t} L_{t}^{w} \\
P_{t+1} C_{2, t+1}^{w} & =\left\{\begin{array}{cc}
\kappa\left(R s_{t}^{w} L_{t}^{w}+R s_{t}^{m} L_{t}^{m}\right) w_{t} & \text { if married } \\
R s_{t}^{w} w_{t} L_{t}^{w} & \text { otherwise }
\end{array}\right.
\end{aligned}
$$

where $E_{t}$ is the conditional expectation operator. $\eta^{m}$ is the emotional utility (or "love") she obtains from her husband, which is a random variable with a distribution function $F^{m}$. Bhaskar (2011) also introduces a similar "love" variable.

\section{A Representative Man's Optimization Problem}

The optimization problem for a representative man is similar:

$$
\max u\left(C_{1 t}^{m}\right)+v\left(1-L_{t}^{m}\right)+\beta E_{t}\left[u\left(C_{2, t+1}^{m}\right)+\eta^{w}\right]
$$

with the budget constraint

$$
\begin{aligned}
P_{t} C_{1 t}^{m} & =\left(1-s_{t}^{m}\right) w_{t} L_{t}^{m} \\
P_{t+1} C_{2, t+1}^{m} & =\left\{\begin{array}{cc}
\kappa\left(R s_{t}^{w} L_{t}^{w}+R s_{t}^{m} L_{t}^{m}\right) w_{t} & \text { if married } \\
R s_{t}^{m} w_{t} L_{t}^{m} & \text { otherwise }
\end{array}\right.
\end{aligned}
$$

\section{The Marriage Market ${ }^{3}$}

We follow Du and Wei (2013) in modeling the marriage market. Specifically, every woman (or man) ranks all members of the opposite sex by a combination of two criteria: (1) the level of wealth (which is determined solely by the first-period savings), and (2) the size of "love" she/he can obtain from her/his spouse. The weights on the two criteria are implied by the utility functions specified earlier. More precisely, woman $i$ prefers a higher ranked man to a lower ranked one, where the rank on man $j$ is given by $u\left(c_{2 w, i, j}\right)+\eta_{j}^{m}$. Symmetrically, man $j$ assigns a rank to woman $i$ based on the utility he can obtain from her $u\left(c_{2 m, j, i}\right)+\eta_{i}^{w}$. To ensure that the preference is strict for both men and women, whenever there is a tie in terms of the above criteria, we break the tie by assuming that a woman prefers $j$ if $j<j^{\prime}$ and a man does the same. Note that "love" is not in the eyes of a beholder in the sense that every woman (man) has the same ranking over men (women).

The marriage market is assumed to follow the Gale-Shapley algorithm (Gale and Shapley, 1962). We assume that the density functions of $\eta^{m}$ and $\eta^{w}$ are continuously differentiable. Since all men (women) in the marriage market have identical problems, they make the same savings decisions. In equilibrium, a positive assortative matching emerges for those men and women who are married. In other words, there exists a mapping $M$ from $\eta^{w}$ to

\footnotetext{
${ }^{3}$ We use the word "market" informally here. The pairing of husbands and wives is not done through prices.
} 
$\eta^{m}$ such that

$$
1-F^{w}\left(\eta^{w}\right)=\phi\left(1-F^{m}\left(M\left(\eta^{w}\right)\right)\right) \Leftrightarrow M\left(\eta^{w}\right)=\left(F^{m}\right)^{-1}\left(1-\frac{1-F^{w}\left(\eta^{w}\right)}{\phi}\right)
$$

For simplicity, we assume that $\eta^{w}$ and $\eta^{m}$ are drawn from the same distribution, $F^{w}=$ $F^{m}=F$. The lowest possible value of emotional utility $\eta^{\text {min }}$ is sufficiently small (which can be negative) so that some women and some men may not get married. Let $\bar{\eta}^{w}$ and $\bar{\eta}^{m}$ denote the threshold values for women's and men's emotional utilities in equilibrium, respectively. Only women (men) with emotional utilities higher than the threshold value $\bar{\eta}^{w}\left(\bar{\eta}^{m}\right)$ will get married. In other words,

$$
\bar{\eta}^{w}=\max \left\{u_{2 m, n}-u_{2 m}, M^{-1}\left(\bar{\eta}^{m}\right)\right\} \text { and } \bar{\eta}^{m}=\max \left\{u_{2 w, n}-u_{2 w}, M\left(\bar{\eta}^{w}\right)\right\}
$$

where $u_{2 m, n}$ and $u_{2 w, n}$ denote the second period utilities of a single man and a single woman, respectively.

For woman $i$, given all her rivals' and men's savings decisions and $\eta^{w}$, her second period utility is

$$
\delta_{i}^{w} u\left(\frac{\kappa\left(R s_{i}^{w} w L_{i}^{w}+R s^{m} w L^{m}\right)}{P_{t+1}}\right)+\left(1-\delta_{i}^{w}\right) u\left(\frac{R s^{w} w L^{w}}{P_{t+1}}\right)+\int_{\tilde{\eta}_{i}^{w} \geq \bar{\eta}^{w}} M\left(\tilde{\eta}_{i}^{w}\right) d F\left(\eta_{i}^{w}\right)
$$

where $\tilde{\eta}_{i}^{w}=u\left(\frac{\kappa\left(R s_{i}^{w} w L_{i}^{w}+R s^{m} w L^{m}\right)}{P_{t+1}}\right)-u\left(\frac{\kappa\left(R s^{w} w L^{w}+R s^{m} w L^{m}\right)}{P_{t+1}}\right)+\eta_{i}^{w} . \delta_{i}^{w}$ is the probability that woman $i$ will get married,

$$
\begin{aligned}
\delta_{i}^{w} & =\operatorname{Pr}\left(u\left(\frac{\kappa\left(R s_{i}^{w} w L_{i}^{w}+R s^{m} w L^{m}\right)}{P_{t+1}}\right)-u\left(\frac{\kappa\left(R s^{w} w L^{w}+R s^{m} w L^{m}\right)}{P_{t+1}}\right)+\eta_{i}^{w} \geq \bar{\eta}^{w} \mid R s^{w} y^{w}, R s^{m} y^{m}\right) \\
& =1-F\left(\bar{\eta}^{w}-u\left(\frac{\kappa\left(R s_{i}^{w} y^{w}+R s^{m} y^{m}\right)}{P_{t+1}}\right)+u\left(\frac{\kappa\left(R s^{w} y^{w}+R s^{m} y^{m}\right)}{P_{t+1}}\right)\right)
\end{aligned}
$$

Due to symmetry, we drop the sub-index $i$ for women. Given men's savings decisions, the first order conditions for her optimization problem are

$$
-u_{1 w}^{\prime} \frac{w_{t} L_{t}^{w}}{P_{t}}+\beta\left[\begin{array}{c}
\delta^{w} \kappa u_{2 w}^{\prime} \frac{R w_{t} L_{t}^{w}}{P_{t+1}}+\left(1-\delta^{w}\right) u_{2 w, n}^{\prime} \frac{R w_{t} L_{t}^{w}}{P_{t+1}}+\frac{\partial \int_{\tilde{\eta}^{w} \geq \bar{\eta}^{w}} M\left(\tilde{\eta}^{w}\right) d F\left(\eta^{w}\right)}{\partial s^{w}} \\
+\frac{\partial \delta^{w}}{\partial s^{w}}\left(u_{2 w}-u_{2 w, n}\right)
\end{array}\right]=0
$$

and

$$
u_{1 w}^{\prime} \frac{\left(1-s_{t}^{w}\right) w_{t}}{P_{t}}+\beta\left[\begin{array}{c}
\delta^{w} \kappa u_{2 w}^{\prime} \frac{R s_{t} w_{t}}{P_{t+1}}+\left(1-\delta^{w}\right) u_{2 w, n}^{\prime} \frac{R s_{t} w_{t}}{P_{t+1}}+\frac{\partial \int_{\tilde{\eta}^{w} \geq \tilde{\eta}^{w}} M\left(\tilde{\eta}^{w}\right) d F\left(\eta^{w}\right)}{\partial L_{t}^{w}} \\
+\frac{\partial \delta^{w}}{\partial L_{t}^{w}}\left(u_{2 w}-u_{2 w, n}\right)
\end{array}\right]-v_{w}^{\prime}=0
$$


where

$$
\begin{aligned}
\frac{\partial \int_{\tilde{\eta}^{w} \geq \bar{\eta}^{w}} M\left(\tilde{\eta}^{w}\right) d F\left(\eta^{w}\right)}{\partial s^{w}} & =\kappa u_{2 w}^{\prime} \frac{R w L^{w}}{P_{t+1}}\left[\int_{\bar{\eta}^{w}} M^{\prime}\left(\eta^{w}\right) d F\left(\eta^{w}\right)+M\left(\bar{\eta}^{w}\right) f\left(\bar{\eta}^{w}\right)\right] \\
\frac{\partial \delta^{w}}{\partial s^{w}} & =f\left(\bar{\eta}^{w}\right) \kappa u_{2 w}^{\prime} \frac{R w L^{w}}{P_{t+1}}
\end{aligned}
$$

By (3.3) and (3.4), we have

$$
\frac{w_{t}}{P_{t}}=\frac{v_{w}^{\prime}}{u_{1 w}^{\prime}}
$$

The optimization problem for a representative man is similar:

$$
\max u\left(C_{1 t}^{m}\right)+v\left(1-L_{t}^{m}\right)+\beta E_{t}\left[u\left(C_{2, t+1}^{m}\right)+\eta^{w}\right]
$$

with the budget constraint

$$
\begin{aligned}
P_{t} C_{1 t}^{m} & =\left(1-s_{t}^{m}\right) w_{t} L_{t}^{m} \\
P_{t+1} C_{2, t+1}^{m} & =\left\{\begin{array}{cc}
\kappa\left(R s_{t}^{w} L_{t}^{w}+R s_{t}^{m} L_{t}^{m}\right) w_{t} & \text { if married } \\
R s_{t}^{m} w_{t} L_{t}^{m} & \text { otherwise }
\end{array}\right.
\end{aligned}
$$

The optimization conditions for his savings rate and labor supply are

$$
-u_{1 m}^{\prime} \frac{w_{t} L_{t}^{m}}{P_{t}}+\beta\left[\begin{array}{c}
\delta^{m} \kappa u_{2 m}^{\prime} \frac{R w_{t} L_{t}^{m}}{P_{t+1}}+\left(1-\delta^{m}\right) u_{2 m, n}^{\prime} \frac{R w_{t} L_{t}^{m}}{P_{t+1}}+\frac{\partial \int_{\tilde{\eta}^{m} \geq \bar{\eta}^{m}} M\left(\tilde{\eta}^{m}\right) d F\left(\eta^{m}\right)}{\partial s^{m}} \\
+\frac{\partial \delta^{m}}{\partial s^{m}}\left(u_{2 m}-u_{2 m, n}\right)
\end{array}\right]=0
$$

and

$$
\frac{w_{t}}{P_{t}}=\frac{v_{m}^{\prime}}{u_{1 m}^{\prime}}
$$

respectively.

On the supply side, all equilibrium conditions other than the labor market clearing condition remain the same. If we normalize the measure of the young cohort to be one, then the labor market clearing condition becomes

$$
L_{T t}+L_{N t}=\frac{1}{1+\phi} L_{t}^{w}+\frac{\phi}{1+\phi} L_{t}^{m}
$$

We now define an equilibrium for such an economy.

Definition 2 An equilibrium is a set $\left\{\left(s_{t}^{w}, L_{t}^{w}\right),\left(s_{t}^{m}, L_{t}^{m}\right), K_{T, t+1}, K_{N, t+1}, L_{T t}, L_{N t}, P_{N t}\right\}$ that satisfies the following conditions:

(i) The savings and labor supply decisions by women and men, $\left(s_{t}^{w}, L_{t}^{w}\right)=\left\{s_{i t}^{w}, s_{-i, t}^{w}, L_{i t}^{w}, L_{-i, t}^{w}\right\}$ 
and $\left(s_{t}^{m}, L_{t}^{m}\right)=\left\{s_{i t}^{m}, s_{-i, t}^{m}, L_{i t}^{m}, L_{-i, t}^{m}\right\}$, maximize their utilities, respectively,

$$
\begin{aligned}
\left(s_{i t}^{w}, L_{i t}^{w}\right) & =\arg \max \left\{V_{t}^{w} \mid\left(s_{-i, t}^{w}, L_{-i, t}^{w}\right),\left(s_{t}^{m}, L_{t}^{m}\right), K_{T, t+1}, K_{N, t+1}, L_{T t}, L_{N t}, P_{N t}\right\} \\
\left(s_{j t}^{m}, L_{j t}^{m}\right) & =\arg \max \left\{V_{t}^{m} \mid\left(s_{t}^{w}, L_{t}^{w}\right),\left(s_{-j, t}^{m}, L_{-j, t}^{m}\right), K_{T, t+1}, K_{N, t+1}, L_{T t}, L_{N t}, P_{N t}\right\}
\end{aligned}
$$

(ii) The markets for both goods and factors clear, and firms' profits are maximized. In other words, $\left\{K_{T, t+1}, K_{N, t+1}, L_{T t}, L_{N t}, P_{N t}\right\}$ solves (2.2), (2.3), (2.4), (2.5), (2.6) and (3.8).

We now consider an unanticipated shock to the sex ratio, i.e., a rise in the sex ratio for the young cohort from one to $\phi(>1)$ from period $t$ onwards. The nature of the shock is motivated by facts about the sex ratio in China. Since a severe sex ratio imbalance for the pre-marital age cohort is a relatively recent phenomenon, the older generations' savings decisions were largely made when there was no severe sex ratio imbalance. As the shock is unanticipated, (2.2) and (2.4) do not hold in period $t$.

As in the benchmark model, the market clearing condition for the non-tradable good can be re-written as

$$
\frac{P_{N t} A_{N t} K_{N t}^{\alpha_{N}} L_{N t}^{1-\alpha_{N}}}{\alpha_{N}^{\alpha_{N}}\left(1-\alpha_{N}\right)^{1-\alpha_{N}}}=\gamma\left(R s_{t-1} w_{t-1}+\left(1-s_{t}\right) w_{t}\right)
$$

where $s_{t}=\frac{\phi}{1+\phi} s_{t}^{m}+\frac{1}{1+\phi} s_{t}^{w}$ is the aggregate savings rate by the young cohort in period $t$.

By (2.3) and (2.5), we have

$\frac{1}{\alpha_{T}^{\alpha_{T}}\left(1-\alpha_{T}\right)^{1-\alpha_{T}}}\left(1-\alpha_{T}\right) A_{T t}\left(\frac{K_{T t}}{1-L_{N t}}\right)^{\alpha_{T}}=\frac{1}{\alpha_{N}^{\alpha_{N}}\left(1-\alpha_{N}\right)^{1-\alpha_{N}}} P_{N t}\left(1-\alpha_{N}\right) A_{N t}\left(\frac{K_{N t}}{L_{N t}}\right)^{\alpha_{N}}$

We assume that $u(C)=\ln C$. We let $L_{t}$ denote the aggregate labor supply in period $t$, and assume that the utility function for leisure satisfies the feature ${ }^{4}$

$$
\frac{2\left(v^{\prime \prime}\right)^{2}}{v^{\prime}}+\frac{v^{\prime}}{L^{2}}-\frac{v^{\prime \prime}}{L}-v^{\prime \prime \prime}>0
$$

If the country stays at the initial equilibrium (before period $t$ ) with non-negative net foreign assets, then we can show the following proposition:

Proposition 2 Assume that the per period utility function is of $\log$ form, $u(C)=\ln C$, for everyone, and that $\eta$ is drawn from a uniform distribution. As the sex ratio (in the young cohort) rises in period $t$, a representative man increases his savings rate and labor supply, while the changes in a representative woman's savings and labor supply are ambiguous. The real exchange rate depreciates.

\footnotetext{
${ }^{4}$ It is easy to show that utility function $v(1-L)=\frac{B(1-L)^{1-\theta}}{1-\theta}(\theta \geq 1)$ satisfies the assumption.
} 
Proof. See Appendix B.

A few remarks are in order. First, it is perhaps not surprising that the representative man raises his savings rate and labor supply in response to a rise in the sex ratio since the need to compete in the marriage market becomes greater. Why is the impact of a higher sex ratio on a representative woman's savings rate and labor supply ambiguous? The answer is that a higher sex ratio produces two offsetting effects for her. On the one hand, as she anticipates more savings and labor supply from her future husband, she can free-ride and does not need to sacrifice her first-period consumption and leisure as much as she otherwise would have to. On the other hand, precisely because men have increased their savings rate in the first period in response to a higher sex ratio, they will be more reluctant to share their wealth with a woman with both a low wealth and a low emotional utility. The last point raises the probability that low-savings women may not get married. Since the representative woman also prefers marriage than spinsterhood, she may raise her savings rate as well as labor supply to improve her chance in the marriage market. Because the two effects go in opposite directions, the net effect of a higher sex ratio on a representative woman's savings is ambiguous.

Second, why do the aggregate savings rate and labor supply rise unambiguously in response to a rise in the sex ratio even when women reduce their savings as well as labor supplies? The answer comes from both an intensive margin and an extensive margin. On the intensive margin, the increment in the representative man's savings (and labor supplies) can be shown to be greater than the reduction in the representative woman's savings (and labor supplies). Heuristically, the representative man raises his savings rate (and labor supply) for two separate reasons: in addition to improving his relative standing in the marriage market, he wants to smooth his consumption over the two periods and would raise his savings rate to make up for the lower wealth by his future wife. The more his future wife is expected to cut down her savings, the more he would have to raise his own savings (and labor supply) to compensate. This ensures that his incremental savings (and labor supply) is more than enough to offset any reduction in his future wife's savings (and labor supply). On the extensive margin, a rise in the sex ratio implies a change in the mix of the population with relatively more higher-saving (and higher-labor-supply) men and relatively fewer lower-saving (and lower-labor-supply) women. While both margins contribute to a rise in the aggregate savings rate, we can verify in calibrations that the intensive margin is quantitatively more important.

Third, once we obtain an increase in the aggregate savings rate, the logic from the previous one-gender benchmark model applies. In particular, the relative price of the nontradable good declines and hence the real exchange rate depreciates.

Fourth, the assumption of uniform distribution of the emotional utility greatly simplifies the calculation and allows us to obtain analytical results. However, this assumption may 
not be realistic. In numerical examples in the following section, we assume a more realistic distribution (normal distribution). We find very similar qualitative results on savings and real exchange rates as in Proposition 2. We also do not assume different elasticities of labor supply for women and men for technical simplicity. However, we can relax this assumption by assuming different utilities on leisure for women and men. To be more specific, we consider utility function $v_{w}$ that generates a more elastic women's labor supply than men's. The main qualitative results may still hold under certain conditions, for instance, by the proof in Appendix B, we can find one sufficient condition for an increase in the aggregate labor supply that

$$
\frac{s_{t}^{m}}{L_{t}^{m}} \frac{d L_{t}^{m}}{d s_{t}^{m}} \geq\left(1+\frac{L_{t}^{w}}{d L_{t}^{w} / d s_{t}^{w}}\right)^{-1}
$$

where $\frac{s_{t}^{m}}{L_{t}^{m}} \frac{d L_{t}^{m}}{d s_{t}^{m}}$ is related to the elasticity of labor supply by men. When men's labor supply is sufficiently elastic, a similar argument as in the previous analysis applies, and hence the aggregate labor supply goes up.

Similar to the benchmark model with a single gender, once the shock is observed and taken into account in period $t+1,(2.2)$ and (2.4) hold in equilibrium. By solving (2.2), (2.3), (2.4), and (2.5), we have

$$
P_{N t}=R^{\frac{\alpha_{N}-\alpha_{T}}{1-\alpha_{T}}} \text { and } P_{t+1}=R^{\frac{\gamma\left(\alpha_{N}-\alpha_{T}\right)}{1-\alpha_{T}}}
$$

This means that the real exchange rate will return to their previous values after one period.

\subsection{Capital adjustment costs and a prolonged effect on the ex- change rate}

Without additional frictions, a shock to the sex ratio can only affect the real exchange rate for one period. If there are capital adjustment costs in each sector, the effect on the real exchange rate can be prolonged. As is standard in the literature, we assume a quadratic capital adjustment cost, then the optimization problems for firms in the tradable good sector and the non-tradable good sector become, respectively,

$$
\max E_{t} \sum_{\tau=0}^{\infty}(R)^{-\tau}\left[Q_{T, t+\tau}-w_{t+\tau} L_{T, t+\tau}-I_{T, t+\tau}\right]
$$

and

$$
\max E_{t} \sum_{\tau=0}^{\infty}(R)^{-\tau}\left[P_{N, t+\tau} Q_{N, t+\tau}-w_{t+\tau} L_{N, t+\tau}-I_{N, t+\tau}\right]
$$


Raising the capital to $K_{i, t+1}$ in period $t+1$ requires time $t$ investment $I_{i t}$ to satisfy

$$
I_{i t}=K_{i, t+1}-(1-\delta) K_{i t}+\frac{b}{2}\left(\frac{K_{i, t+1}}{K_{i t}}-1\right)^{2} K_{i t}, i=T, N
$$

Then (2.2) and (2.4) become, respectively,

$$
\begin{aligned}
R= & 1-\delta+\frac{1}{\alpha_{T}^{\alpha_{T}}\left(1-\alpha_{T}\right)^{1-\alpha_{T}}} \alpha_{T} A_{T, t+1}\left(\frac{L_{T, t+1}}{K_{T, t+1}}\right)^{1-\alpha_{T}} \\
& -b R\left(\frac{K_{T, t+1}}{K_{T t}}-1\right)+\frac{b}{2}\left(\left(\frac{K_{T, t+2}}{K_{T, t+1}}\right)^{2}-1\right) \\
R= & 1-\delta+\frac{1}{\alpha_{N}^{\alpha_{N}}\left(1-\alpha_{N}\right)^{1-\alpha_{N}}} P_{N, t+1} \alpha_{N} A_{N, t+1}\left(\frac{L_{N, t+1}}{K_{N, t+1}}\right)^{1-\alpha_{N}} \\
& -b R\left(\frac{K_{N, t+1}}{K_{N t}}-1\right)+\frac{b}{2}\left(\left(\frac{K_{N, t+2}}{K_{N, t+1}}\right)^{2}-1\right)
\end{aligned}
$$

Without capital adjustment costs, i.e., $b=0$, the price of the non-tradable good will go back to its equilibrium level in period $t+1$. With capital adjustment costs, i.e., $b>0$, then

$P_{N, t+1}=\frac{\frac{1}{\alpha_{T}^{\alpha_{T}}\left(1-\alpha_{T}\right)^{1-\alpha_{T}}} \alpha_{T} A_{T t+1}\left(\frac{L_{T t+1}}{K_{T t+1}}\right)^{1-\alpha_{T}}-b R\left(\frac{K_{T, t+1}}{K_{T t}}-\frac{K_{N, t+1}}{K_{N t}}\right)-\frac{b}{2}\left(\left(\frac{K_{T, t+2}}{K_{T, t+1}}\right)^{2}-\left(\frac{K_{N, t+2}}{K_{N, t+1}}\right)^{2}\right)}{\frac{1}{\alpha_{N}^{\alpha_{N}}\left(1-\alpha_{N}\right)^{1-\alpha_{N}}} \alpha_{N} A_{N t+1}\left(\frac{L_{N t+1}}{K_{N t+1}}\right)^{1-\alpha_{T}}}$

$P_{N, t+1}$ is now a function of $\frac{K_{T, t+1}}{K_{T t}}, \frac{K_{N, t+1}}{K_{N t}}, \frac{K_{T, t+2}}{K_{T, t+1}}$ and $\frac{K_{N, t+2}}{K_{N, t+1}}$. If $\frac{K_{T, t+1}}{K_{T t}} \neq \frac{K_{N, t+1}}{K_{N t}}$ and $\frac{K_{T, t+2}}{K_{T, t+1}} \neq \frac{K_{N, t+2}}{K_{N, t+1}}, P_{N, t+1}$ is not a constant. This means that, with capital adjustment costs, the price of the non-tradable good does not return immediately to its long-run equilibrium level. As a result, a rise in the sex ratio can have a long-lasting and depressing effect on the real exchange rate.

\subsection{Two large countries}

We now turn to a world with two large countries: Home and Foreign. Assume that they are identical in every respect except for their sex ratios. Specifically, in period $t$, the sex ratio of the young cohort in Home rises from one to $\phi(\phi>1)$, while Foreign always has a balanced sex ratio. Households in each country consume a tradable good and a non-tradable good.

$$
C_{t}=\frac{C_{N t}^{\gamma} C_{T t}^{1-\gamma}}{\gamma^{\gamma}(1-\gamma)^{1-\gamma}} \text { and } C_{t}^{*}=\frac{\left(C_{N t}^{*}\right)^{\gamma}\left(C_{T t}^{*}\right)^{1-\gamma}}{\gamma^{\gamma}(1-\gamma)^{1-\gamma}}
$$


where $C_{t}$ and $C_{t}^{*}$ represent home and foreign consumption indexes, respectively. Since we choose the tradable good as the numeraire, the consumer price index is $P_{t}=P_{N t}^{\gamma}$, where $P_{N t}$ is the price of the home produced non-tradable good. Similarly, the consumer price index in Foreign is $P_{t}^{*}=\left(P_{N t}^{*}\right)^{\gamma}$.

The rise in Home's sex ratio in period $t$ is assumed to be unanticipated. As a result, (2.2) and (2.4) fail in both Home and Foreign. Let $R_{t}$ denote the equilibrium world interest rate (which is endogenous). Suppose households and firms know $R_{t}$, they will then optimize their decisions (which leads to the equilibrium with world interest rate $R_{t}$ ). Since the two countries are identical except for the sex ratios, comparing the prices of non-tradable goods in Home and Foreign is similar to considering an exercise that raises the sex ratio from one (Foreign) to an unbalanced level (Home) when all agents know $R_{t}$. By Proposition 2, we obtain the result that Home will have a lower relative non-tradable good price than Foreign. This means that Home will experience a real exchange rate depreciation relative to Foreign in period $t$. Similar to the previous analysis, Home will also experience a real appreciation in period $t+1$.

\section{Some Numerical Examples}

Before we go to our empirical results, we provide some numerical examples, both to illustrate the possible quantitative effects of a rise in the sex ratio, and to explore robustness of the main results to different values of the key parameters. To build in more realism relative to the benchmark model, we introduce three modifications. First, we assume that each cohort lives 50 periods, working in the first 30 periods, and retiring in the remaining 20 periods. Second, we follow the literature on the real exchange rate and introduce a distribution (transporting, marketing, and sales) cost for tradable goods. Third, we also introduce capital adjustment costs.

\subsection{An OLG model in which a cohort lives 50 periods}

For a representative man or woman, if he or she gets married, the marriage takes place in the (exogenously predetermined) $\tau$ th period, which is common for both men and women. To determine the value of $\tau$, we have to balance two considerations. On the one hand, if it is the representative agent's own marriage, it would be reasonable to set a relatively low value for $\tau$, perhaps around 5 . On the other hand, data suggests that a big part of the savings and work effort responses to higher sex ratios come from actions taken by parents for their children (Wei and Zhang, 2011a and 2011b). While our model does not formally feature parental savings or parental income transfers to children, we do not want the simulations to ignore completely this important data feature. If $\tau$ is to represent the number of working years a parent has when his/her child gets married, we may set a 
relatively high value, perhaps around 25 . As a compromise, we set $\tau=15$ as the benchmark value in our simulations.

For a robustness check, we will also report results when $\tau=10$. One may also think that $\tau$ should take a value greater than 15 . Generally speaking, the greater the value of $\tau$, the stronger is the real exchange rate response to a given rise in the sex ratio.

We now describe the representative woman's optimization problem. Her objective function is

$$
\max \sum_{t=1}^{\tau-1} \beta^{t-1} U_{t}^{w}+E_{1}\left[\sum_{t=\tau}^{50} \beta^{t-1}\left(U_{t}^{w}+\eta^{m}\right)\right]
$$

where

$$
U_{t}^{w}=\left\{\begin{array}{cc}
u\left(c_{t}^{w}\right)+v\left(1-L_{t}^{w}\right) & \text { if } t \leq 30 \\
u\left(c_{t}^{w}\right)+v(1) & \text { if } t>30
\end{array}\right.
$$

For $t<\tau$, when she is still single, the intertemporal budget constraint is

$$
A_{t+1}=R\left(A_{t}+y_{t}^{w}-P_{t} c_{t}^{w}\right)
$$

where $A_{t}$ is the wealth held by her at the beginning of period $t . y_{t}^{w}=w_{t} L_{t}^{w}$ is her labor income at age $t$. After marriage $(t \geq \tau)$, her family budget constraint becomes

$$
A_{t+1}^{H}=\left\{\begin{array}{cc}
R\left(A_{t}^{H}+w_{t}\left(L_{t}^{w}+L_{t}^{m}\right)-\frac{P_{t} c_{t}^{H}}{\kappa}\right) & \text { if } t \leq 30 \\
R\left(A_{t}^{H}-\frac{P_{t} c_{t}^{H}}{\kappa}\right) & \text { if } t>30
\end{array}\right.
$$

where $A_{t}^{H}$ is the level of family wealth at the beginning of period $t . c_{t}^{H}$ is the (common) consumption good consumed by the wife and the husband, which takes the same form as in the two-period OLG model. If she remains single, her budget constraint after period $\tau$ is

$$
A_{t+1}^{w, n}=\left\{\begin{array}{cc}
R\left(A_{t}^{w, n}+w_{t} L_{t}^{w}-P_{t} c_{t}^{w, n}\right) & \text { if } t \leq 30 \\
R\left(A_{t}^{w, n}-P_{t} c_{t}^{w, n}\right) & \text { if } t>30
\end{array}\right.
$$

The representative man's optimization problem is similar.

\subsection{Parameters used in the examples}

We assume the same sub-utility function on leisure as in the two-period model, $v(1-$ $L)=B \ln (1-L)$. Parameter $B$ is set to match the fact that the equilibrium labor supply (under a balanced sex ratio) is $1 / 3$ (corresponding to 8 working hours per day). We assume that there is a lower bound for labor supply $\bar{L}, L_{t}^{i} \geq \bar{L}(i=w, m)$. This is to prevent women from reducing their labor supply too much and generating an unrealistic reduction in their labor supply when the sex ratio rises. A possible justification for the lower bound is this: 
It may be unrealistic for most people to find a job that allows for downward adjustment of working hours in a flexible manner. Part-time jobs such as babysitting are not generally available in all industries. On the other hand, one can often do overtime or moonlighting for a second job. In other words, it is relatively easier to adjust labor supply upward in a fractional manner than to adjust it downward. We set $\bar{L}=1 / 3$. This value is chosen so that both men and women would supply labor around $1 / 3$ in the equilibrium with a balanced sex ratio. [In unreported simulations, we verify that relaxing this assumption does not dramatically change the quantitative results on the overall RER response to a higher sex ratio (although the responses by some other variables could change more noticeably).] Also as in our previous analysis, we may assume different utilities on leisure for women and men. However, this only adds great difficulties to our computation. Once the elasticities of labor supply for women and men do not differ that much, we obtain the same qualitative results as in Proposition 4.

We consider one period in our model as one year. Following Song, Storesletten, and Zilibotti (2011), we take 1.0175 as the annual gross interest rate in China. The subjective discount factor is set at $\beta=1 / R$. We infer the labor intensities in the tradable and nontradable good sectors from China's Input-Output Table in 2007. More precisely, we do this in two steps. First, we compute the sum of exports and imports relative to gross sectoral output for each sector, and define those sectors whose ratios are above the median as "tradables," and the rest as "non-tradables." By this criterion, almost all manufacturing sectors are classified as tradables and almost all service sectors as non-tradables. We combine the two groups of sectors into two aggregated sectors. Second, we compute the shares of labor costs in total production costs for the two aggregated sectors. By this procedure, $\alpha_{T}=0.69$ and $\alpha_{N}=0.49$.

Burstein, Neves, and Rebelo (2003) find that the costs of distributing tradable goods (transportation, wholesaling, and retailing) are important for understanding the movements in the RER. For this reason, we assume that consuming the tradable good requires the use of distribution services (represented by the use of the non-tradable good). ${ }^{5}$ Since the total available non-tradable good can be either consumed or used to supply distribution services, we have, in equilibrium,

$$
Q_{N t}=C_{N t}+\zeta C_{T t}
$$

\footnotetext{
${ }^{5}$ No qualitative results will change if we add the distribution cost to our benchmark model. Mathematically, we can show that for any $0 \leq \zeta<1$, under the assumption in Propositions 2 and 4, the aggregate demand for the non-tradable good, $C_{N t}+\zeta C_{T t}$, is a decreasing function of the sex ratio, which ensures the same results in Propositions 2 and 4. Intuitively, the aggregate demand for the non-tradable good consists of (i) the non-tradable consumption good directly demanded by consumers and (ii) the non-tradable services used in distributing the tradable consumption good (which is positively correlated with the demand for the tradable good). As the sex ratio rises, the aggregate savings rate rises. Then the demand for both the tradable and the non-tradable consumption goods falls which in turn leads to a fall in the aggregate demand for the non-tradable goods. Based on the same logic, the relative price of the non-tradable good falls which in turn leads to a real exchange rate depreciation.
} 
This will only change the market clearing condition for the non-tradable good and the final price of the tradable good

$$
Q_{N t}=\frac{\gamma P_{t}\left(C_{2 t}+C_{1 t}\right)}{P_{N t}}+\zeta \frac{(1-\gamma) P_{t}\left(C_{2 t}+C_{1 t}\right)}{P_{T t}}
$$

where

$$
P_{T t}=1+\zeta P_{N t}
$$

The distribution margin (the fraction of distribution cost in the final tradable good price) is

$$
\mu=\frac{\zeta P_{N t}}{1+\zeta P_{N t}}
$$

We set $\gamma=0.44$ to match the Chinese data - the share of all non-tradable sectors collectively accounts for $44 \%$ of the final consumption good basket. Following Burstein, Neves, and Rebelo (2003), we choose parameter $\zeta$ so that the distribution margin $\mu$ is $50 \%$. We also consider $\mu=0.25$ as a robustness check.

For the congestion index in the within-marriage consumption allocation, we set $\kappa=0.8$. We also choose $\kappa=0.7$ and 0.9 for robustness checks. As in Song, Storesletten, and Zilibotti (2011), we set the annual capital depreciation rate $\delta$ to be 0.1 .

For the quadratic capital adjustment costs in production, $\frac{b}{2}\left(\frac{I_{t}}{K_{t}}-\delta\right)^{2} K_{t}$, there is no consensus on the adjustment parameter $b$. Its value ranges from 0.5 to 20 in the literature. Following Gali, López-Salido, and Vallés (2004), we choose the value for parameter $b$ such that the elasticity of the investment-capital ratio with respect to Tobin's $Q$ is one in the benchmark. ${ }^{6}$ This implies that $b=10$. Based on data on a panel of Chinese manufacturing plants, Wu (2011) estimates a capital adjustment function (embedded in a structural

${ }^{6}$ Tobin's $\mathrm{Q}$ for firm $i$ is defined as

$$
q_{i t}=\frac{P_{K_{i}^{\prime} t}}{P_{I t}}
$$

where $P_{K_{i}^{\prime} t}$ denotes the marginal value of capital at firm $i$ installed at the beginning of time $t+1$ and $P_{I t}$ is the price of investment goods, which is unity. Profit maximization implies that the value of a marginal unit of installed capital is equal to its cost. That is

$$
P_{K_{i}^{\prime} t}=\frac{P_{I t}}{M P I_{i t}}=\frac{1}{M P I_{i t}}
$$

where

$$
M P I_{i t}=\frac{d K_{i t+1}}{d I_{i t}}
$$

Since $K_{i t}$ is predetermined, under the quadratic capital adjustment cost function,

$$
q_{i t}=1+b\left(\frac{K_{i t+1}}{K_{i t}}-1\right)
$$

Then, the elasticity of investment-capital ratio with respect to Tobin's Q in the steady state is

$$
\frac{d\left(I_{i t} / K_{i t}\right)}{d q_{i t}} \frac{q_{i t}}{I_{i t} / K_{i t}}=\frac{1}{b \delta}
$$


model) that is more complex than ours. Her estimates suggest that the coefficient for the quadratic term in the capital adjustment cost in China can be almost 10 times larger than the corresponding coefficient estimated for the United States by Cooper and Haltiwanger (2006). While we use $b=10$ as our baseline case, we will also consider $b=5$ and 15 for robustness checks.

The Chinese data suggests an interesting (and maybe peculiar) feature about a typical worker's life-time earnings profile. Using data from urban household surveys, Song and Yang (2010) document that a typical worker in China faces a fairly flat life-time (real) earnings profile (although the starting salary of each successive cohort tends to rise fast). Within a given cohort, we also assume a flat earnings profile over time. Since we do not consider an exogenous growth in productivity, we do not feature a steady rise in income from one cohort to the next.

The emotional utility $\eta$ needs to follow a continuously differentiable distribution. We assume a normal distribution which might be more realistic than the uniform distribution used in the analytical model. We follow Du and Wei (2013) to set the mean and the standard deviation of $\eta$. To choose the mean value for emotional utility, we perform the following thought experiment. Holding all other factors constant, we can compute the annual income compensation needed for a representative person to be indifferent between being a life-time bachelor and getting married. Let

$$
C Y_{\tau}=\left\{y_{\tau}+\text { compensation }_{\tau}, y_{\tau+1}+\text { compensation }_{\tau+1}, \cdots, y_{50}+\text { compensation }_{50}\right\}
$$

be a vector of all his future incomes after period $\tau$. Then

$$
u\left(\kappa\left(c_{t}^{w}+c_{t}^{m}\right)\right)+v\left(1-L_{t}^{m}\right)+E(\eta)=u\left(c_{n, t}^{m}\left(C Y_{\tau}\right)\right)+v\left(1-L_{n, t}^{m}\right)
$$

where $c_{n, t}^{m}\left(C Y_{\tau}\right)$ is his consumption function in period $t . L_{t}^{m}$ and $L_{n, t}^{m}$ are period t's labor supplies by a married man and a life-time bachelor, respectively.

Under a balanced sex ratio, we can re-write a representative man's optimization problem as the following

$$
\max _{c_{1 t}^{m}, c_{2 t}^{m}}\left(\sum_{t=1}^{\tau-1} \beta^{t-1}\right)\left[u\left(c_{1 t}^{m}\right)+v\left(1-L_{1 t}^{m}\right)\right]+\left(\sum_{t=\tau}^{50} \beta^{t-1}\right) E_{1}\left[\left(u\left(c_{2 t}^{m}\right)+v\left(1-L_{2 t}^{m}\right)+\eta^{m}\right)\right]
$$

where $c_{1 t}^{m}$ and $c_{2 t}^{m}$ are consumptions before and after period $\tau$, respectively; and $L_{1 t}^{m}$ and $L_{2 t}^{m}\left(L_{2 t}^{m}=0\right.$ for $\left.t>30\right)$ are labor supplies before and after period $\tau$, respectively. In equilibrium, since wage is a constant, $c_{1 t}^{m}, c_{2 t}^{m}, L_{1 t}^{m}$ and $L_{2 t}^{m}$ are also constants. Since we choose parameter $B$ - the parameter for the disutility of work - to let the equilibrium labor 
supply be $1 / 3$, we further re-write the optimization for the representative man as

$$
\max _{c_{1}^{m}, c_{2}^{m}}\left(\sum_{t=1}^{\tau-1} \beta^{t-1}\right)\left[u\left(c_{t}^{m}\right)+\widehat{\beta} E_{1}\left[\left(u\left(c_{2}^{m}\right)+\eta^{m}\right)\right]+t . i . p\right]
$$

where we use t.i.p to denote those terms that are independent of the optimization problem and $\widehat{\beta}=\left(\sum_{t=\tau}^{50} \beta^{t-1}\right) /\left(\sum_{t=1}^{\tau-1} \beta^{t-1}\right)$. The budget constraint in this case is

$$
\begin{aligned}
A_{\tau} & =\frac{R-R^{\tau}}{1-R}\left(w-c_{1}^{m}\right) \\
\left(\sum_{t=\tau}^{50} R^{-(t-\tau)}\right) c_{2}^{m} & =A_{\tau}+\frac{1}{3}\left(\sum_{t=\tau}^{30} R^{-(t-\tau)}\right) w
\end{aligned}
$$

Similar to our two-period OLG model, under a balanced sex ratio, the first order condition with respect to $\frac{A_{\tau}}{\frac{R-R^{\tau}}{1-R}}$ is

$$
-u_{1 m}^{\prime}+\widehat{\beta} \frac{R-R^{\tau}}{1-R}\left[\kappa u_{2 m}^{\prime}\left(\delta^{m}+\left(1-F\left(\bar{\eta}^{m}\right)\right)\right)+\left(1-\delta^{m}\right) u_{2 m, n}^{\prime}\right]=0
$$

where $\delta^{m}=1-F\left(\bar{\eta}^{m}\right)$. Under the log utility assumption, and due to the symmetry between men and women, the first order condition becomes

$$
-\frac{1}{c_{1}^{m}}+\widehat{\beta} \frac{R-R^{\tau}}{1-R} \frac{1}{c_{2}^{m}}=0
$$

Combining (4.1), (4.2) with (4.3), we can solve the model under a balanced sex ratio in which the consumption does not depend on any emotional utility assumptions.

Given $C Y_{\tau}$ and $A_{\tau}$ obtained from the previous solution, we can also compute a life-time bachelor's consumption in each period after age $\tau$. We assume in this paper that emotional utility distributions are the same in all countries. The assumption allows us to use empirical evidence from countries with balanced sex ratios to calibrate the mean and the standard deviation of the normal distribution. Blanchflower and Oswald (2004), by regressing selfreported well-being scores on income, marriage status, and other determinants, estimate that a lasting marriage is, on average, worth $\$ 100,000$ (in 1990 dollars) per year (every year) in the United States during 1972-1998. Since GDP per person employed is about $\$ 48,000$ during the same period, this implies that a lasting marriage per year is worth more than twice the average working income for employed people. We take the ratio of income compensation to the average wage income $m=100,000 / 48,000 \simeq 2.08$ as the benchmark. 
This implies that

$$
C Y_{\tau}=\{\underbrace{(1+m) w L_{n, 2}^{m}, \cdots,(1+m) w L_{n, 2}^{m}}_{t \leq 30}, \underbrace{m w L_{n, 2}^{m} \cdots, m w L_{n, 2}^{m}}_{t>30}\}
$$

Since the United States has a balanced sex ratio over that period, we calibrate the mean value of the emotional utility/love by using the previous model results: ${ }^{7}$

$$
E(\eta)=u\left(c_{n, t}^{m}\left(C Y_{\tau}\right)\right)+v\left(1-L_{n, t}^{m}\right)-\left.\left[u\left(\kappa\left(c_{t}^{w}+c_{t}^{m}\right)\right)+v\left(1-L_{t}^{m}\right)\right]\right|_{\phi_{t}=1}
$$

As a robustness check, we will also consider $m=1$.

As for the standard deviation of emotional utility, we set $\sigma=0.1$ in the benchmark and $\sigma=0.2$ as a robustness check. This is consistent with the empirical results in Blanchflower and Oswald (2004) that the absolute values of the $t$ statistics, $|t . s t a t|=\frac{E(\eta)}{\sigma}$, for the coefficient estimates on the dummy variable "never married" (the United States) or the dummy variable "married" (the United Kingdom) for men and women are between 3 and 16.

For technical reasons, we also assume that there exists an exogenous marriage market friction that everybody in the marriage market faces a small possibility of not getting matched that is independent of the sex ratio. We choose that probability to be $0.001 .^{8}$

We summarize our choices of the parameter values in the following table.

\section{Choice of Parameter Values}

\footnotetext{
${ }^{7}$ Under the log utility assumption, $w$ will disappear when we calculate the mean of the emotional utility $E(\eta)$.

${ }^{8}$ This assumption plays no role in the theoretical analysis but ensures that we obtain real roots in the numerical computations. Small departures from this value have little effect on the quantitative results.
} 


\begin{tabular}{|c|c|c|}
\hline Parameters & Benchmark & Source and robustness checks \\
\hline Annual gross interest rate & $R=1.0175$ & Song, Storesletten, and Zilibotti (2011) \\
\hline Discount factor & $\beta=1 / R$ & \\
\hline \multirow[t]{2}{*}{ Non-tradable sector capital-intensity } & $\alpha_{N}=0.49$ & Authors' calculation \\
\hline & & based on 2007 Chinese input-output table \\
\hline \multirow[t]{2}{*}{ Tradable sector capital-intensity } & $\alpha_{T}=0.69$ & Authors' calculation \\
\hline & & based on 2007 Chinese input-output table \\
\hline Share of non-tradable good & $\gamma=0.44$ & Authors' calculation \\
\hline in the consumption basket & & based on 2007 Chinese input-output table \\
\hline Congestion index & $\kappa=0.8$ & Du and Wei (2013), $\kappa=0.7,0.9$ as robustness checks. \\
\hline Capital adjustment cost & $b=10$ & $b=5,15$ as robustness checks \\
\hline Love, mean & $m=2.08$ & Du and Wei (2013), $m=1$ as a robustness check \\
\hline Love, standard deviation & $\sigma=0.1$ & Du and Wei (2013), $\sigma=0.2$ as a robustness check \\
\hline Marriage age & $\tau=15$ & $\tau=10$ as a robustness check \\
\hline Distribution margin & $\mu=0.5$ & $\mu=0.25$ as a robustness check \\
\hline
\end{tabular}

\subsection{Numerical results}

We solve the multi-period model by iterations. Given a guess for a sequence of the wage rates and future capital accumulation path, we can solve the equilibrium in Definition 3 from equations (3.3), (3.5), (3.6), (3.7), (3.10), (3.13), (3.14), (2.6), and (3.8). By (2.3) or (2.5), we can generate new sequences of the wage rates and capital stocks. If the implied sequences are consistent with our guess, then an equilibrium is considered found. Otherwise, we update the guess for the sequences and iterate until we achieve convergence.

To calibrate the size of the sex ratio shock, we use Chinese demographic data as a guide (see Wei and Zhang, 2011a). We let the sex ratio in the model rise continuously and smoothly from 1 to 1.15 in period 6 , and continue to rise until it reaches 1.20 in period 25 and stay at that level in all subsequent periods. ${ }^{9}$

The simulation results for the baseline case are shown in Figure 1. As the sex ratio rises (by following a pre-specified path), the real exchange rate depreciates by more than 4 percent by year 6 , and continues to depreciate to a cumulative 6.8 percent by year 16 . Starting from year 17, the RER begins to appreciate, and the cumulative changes converge to zero eventually. Figure 1 shows that the effect of a rise in the sex ratio has a long-lasting and economically significant effect on the RER for a number of periods. The RER remains more than 5 percent below the long-run equilibrium value for more than 10 years. In the figure, we also consider two robustness checks by varying the value of $\kappa$. As it turns out, the RER response is not sensitive to these changes in $\kappa$.

\footnotetext{
${ }^{9}$ The sex ratio for the pre-marital age cohort in China was close to normal before 2000 but rose to 1.15 by 2007 and is projected to be 1.20 around 2025 (Wei and Zhang, 2011a).
} 
In Figure 2, we present how the response pattern changes when we vary the capital adjustment cost. With a higher cost of capital adjustment, $b=15$, the RER depreciation becomes somewhat stronger. The converse is true when the adjustment cost is lowered to $b=5$. Overall, these responses are all economically significant even though the magnitude depends on the exact adjustment cost.

In Figure 3, we report a robustness check when we vary the mean value of emotional utility/love. At a lower value of $m=1$, which is substantially lower than the baseline value inferred from Blanchflower and Oswald (2004), the response of the RER is weaker (but still significant economically). Naturally, when we experiment with a higher value of $m$ (not reported), we obtain a stronger RER response than the baseline simulation.

In Figure 4, we vary the standard deviation of emotional utility. With a larger standard deviation of $\sigma=0.2$, men are more likely to be matched with low-type women and hence they are less desperate to avoid bachelorhood. This causes them to exert less effort to succeed in the marriage market. As a result, the RER response becomes weaker, but is still economically significant.

In Figure 5, we conduct a sensitivity check on the timing of marriage by assuming $\tau=10$ (instead of the baseline value of $\tau=15$ ). The RER depreciation in the first ten periods is even stronger than the baseline case, but the reversal to the long-run steady state occurs earlier (at the 10th period instead of the 15th period).

Finally, in Figure 6, we perform a robustness check on the value of the distribution margin by assuming a very low margin, $\mu=0.25$, which is only half of what is estimated by Burstein, Neves, and Rebelo (2003). In that case, a rise in the sex ratio generates a smaller but still sizable response in the RER.

To summarize, these numerical examples suggest that a rise in the sex ratio can produce an economically meaningful reduction in the real exchange rate for realistic parameter values. Relative to the standard approach to assessing the RER, for example, of the kind used by the International Monetary Fund, the exchange rate of a country with a sex ratio imbalance may appear "undervalued" even with no explicit exchange rate policy or RER targeting. Because the existing literature does not provide a tight guidance on the values of all the parameters, the numerical examples are only suggestive.

\subsection{Other robustness checks}

The rise in the sex ratio occurs around the same time as other developments that could also affect savings and labor supply. We could consider a few such developments (productivity gains, population aging, and pension reforms) and examine if they tend to weaken or strengthen the effects of marriage market competition on the RER.

We start with an exogenous and uniform improvement in productivity in both the tradable and non-tradable sectors. (This could be thought of as a way to represent an 
increase in the country's potential growth rate.) To abstract from the Balassa-Samuelson effect, we use the following production functions in the two sectors:

$$
Q_{T t}=\frac{A_{T t} K_{T t}^{\alpha_{T}}\left(\xi_{t} L_{T t}\right)^{1-\alpha_{T}}}{\alpha_{T}^{\alpha_{T}}\left(1-\alpha_{T}\right)^{1-\alpha_{T}}} \text { and } Q_{N t}=\frac{A_{N t} K_{N t}^{\alpha_{N}}\left(\xi_{t} L_{N t}\right)^{1-\alpha_{N}}}{\alpha_{N}^{\alpha_{N}}\left(1-\alpha_{N}\right)^{1-\alpha_{N}}}
$$

where $\xi_{t}$ is the labor productivity coefficient common to both sectors. In our first numerical experiment, we consider a permanent $10 \%$ increase in $\xi_{t}$ (from 1 to 1.1) at the same time when the sex ratio rises. ${ }^{10}$ The simulation result is presented in Figure 7. We note first that in the new long run equilibrium, we still obtain the fact that $P_{N t}=R^{\frac{\alpha_{N}-\alpha_{T}}{1-\alpha_{T}}}$ and the RER goes back to the same value as in the initial equilibrium. Interestingly, the numerical result shows that the two shocks together leads to a stronger decline in the real exchange rate than either a rise in the sex ratio alone (the thin blue line marked as the benchmark) or a productivity increase alone (the thick black line marked as the case of a "balanced sex ratio"). More precisely, in the first period following the two shocks (when the sex ratio is only moderately unbalanced), the real exchange rate falls by more than 6 percent; however, the RER continues to depreciate, by more than $8 \%$ in period 16 . Interestingly, before the RER goes back to the long run equilibrium, the figure shows the possibility of overshooting, i.e., it appreciates before depreciating again.

We also plot the responses of savings and labor supply in Figures 8 and 9. Interestingly, the aggregate savings rate goes up more with the joint occurence of the two shocks than with either of the two shocks alone. The savings rate reaches a peak value around period 16; after that, the increase in the dis-savings by the old offsets the increase in the savings by the unmarried young people (Figure 8 ). We conjecture that two channels are at play here. First, despite higher future income from higher productivity, the pressure from the marriage market competition remains strong on men. Second, a rise in productivity results in a greater supply of both tradable and non-tradable goods. Since the price of the tradable is set in the world market, this expansion of supply leads to a reduction in the price of the non-tradable. The decline in the price of the non-tradable good may lead labor to reallocate from the non-tradable to the tradable sector. Since capital adjusts sluggishly due to adjustment costs, wage rises at a slower pace than output in the tradable good sector. This implies (and is confirmed in the simulation) that consumption rises at a slower pace than output, leading to a rise in aggregate savings. As time passes by, the capital stock adjusts to the new long run equilibrium, and the non-tradable good sector expands as well.

The aggregate labor supply rises quickly in the first 16 periods and stays high as it approaches the new long run equilibrium (Figure 9). Numerically, there is very little

\footnotetext{
${ }^{10}$ The rapid economic growth in China starts before 2000 (when the sex ratio starts rising). For technical convenience, we simply let the shocks on labor productivity and sex ratio occur at the same time. In unreported numerical experiments, we show that, assuming the labor productivity shock to occur several years before the rise in the sex ratio does not change the quantitative results very much.
} 
difference in the labor supply response to a higher sex ratio with or without a productivity increase. This suggests that the increased labor supply due to marriage market competition is essentially unaffected by the productivity change. To summarize, putting the two channels together, we see that having a productivity increase tends to strengthen rather than weaken the RER effect from a higher sex ratio.

We now consider a second experiment: population aging, represented by a reduction by 10 percent in the size of all cohorts in period $t$ and later. This takes place at the same time as the sex ratio rises. Intuitively, the competitive savings and competitive labor supply channels should be weaker in this experiment since the relative weight of the cohorts with unbalanced sex ratio declines. The numerical results reported in Figure 10 confirm our conjecture. Nonetheless, the impact of a rise in the sex ratio on the RER is still economically significant. The RER declines by close to 6 percent in period 16. This experiment suggests that population aging may only marginally weaken the impact of a higher sex ratio on the RER.

We consider a third experiment: a pension reform similar to what took place in China in the 1990s. We assume that retired workers do not work but receive pensions. Following He, Lei, and Zhu (2014), the pension for an age $j$ worker who retires at $t-(j-30)$ is given by

$$
S S_{j, t}=\theta\left[v \bar{E}_{j, t}+(1-v) A I M E\right]
$$

where $\theta$ represents the target replacement ratio, $\bar{E}_{j, t}$ is the average wage in the society, and $A I M E$ represents the life-cycle average monthly wage, similar to Average Indexed Monthly Earnings in the US pension system (hence the acronym). We do not model wage differences for workers of different ages in the same period. Instead, $\bar{E}_{j, t}$ will be the wage at time $t$. We assume that a fraction $\tau^{s}$ (social security tax) of the wage income will be taxed, and set $\tau^{s}=0.2$ in the simulations to be in line with Song et al. (2015). ${ }^{11}$ We represent the pension reform in China by a decline in $\theta$ from $80 \%$ to $60 \%$ and a simultaneous decline in $v$ from $100 \%$ to $60 \%$ (He, Lei, and Zhu, 2014).

The numerical results are presented in Figure 11. With the pension reform taking place at the same time, a rise in the sex ratio yields a very strong initial decline in the RER. In the first period following the joint occurence of the two shocks, the RER depreciates by more than 18 percent. The effect is also long-lasting: the RER depreciation remains above 5 percent for 30 years. The intuition behind this result is straightforward. Since the long run equilibrium wage rate is purely a function of the world interest rate (which is a constant in our model), the pension reform implies a decline in a worker's life-time income, which leads the representative worker to raise both savings and labor supply. This augments the RER depreciation already generated by a rise in the sex ratio. For comparison, the RER trajectory with the pension reform but without a corresponding rise in the sex ratio is

\footnotetext{
${ }^{11}$ For simplicity, we do not assume a balanced government budget.
} 
plotted by the thin blue line marked by the case of a "balanced sex ratio." Clearly, in the first fifteen periods, the RER depreciation is much stronger with the joint occurence of the two shocks than with the pension reform alone.

In the last experiment, we re-compute the labor intensities in the two sectors. In our benchmark, the labor intensity in production is defined as the ratio of wage payment to workers to total value added. However, in the data, the total value added usually includes operating surplus. In a robustness check, we re-compute the labor intensity based on the formula: wage payment/(total value added net of operating surplus). In this case, we obtain a labor intensity of around 0.68 in the tradable good sector and 0.74 in the non-tradable good sector. We re-do the exercise on the impact of a rise in the sex ratio and report the result in Figure 12. While the new labor intensities generate some difference for the result, the difference is small. In other words, a rise in the sex ratio still has a significant impact on the RER.

\section{Some empirics}

Since the effect of an unbalanced sex ratio on the exchange rate is relatively novel, it is useful to present and discuss some empirical evidence. We proceed in three steps. First, on the effects of the sex ratio on savings rate and effective labor supply, we do not have to re-invent the wheel as we can point to relevant evidence from the recent empirical literature. Second, we provide some new evidence on the connection between the sex ratio and the real exchange rate (or the relative price of non-tradable goods) across regions within a country. Third, we present some new cross-country evidence on the relationship between the sex ratio and the real exchange rate.

\subsection{Micro-level evidence on savings}

We first review the evidence in Wei and Zhang (2011a) that a higher sex ratio has led to a rise in the household savings rate in China. At the household level, families with a son tend to save more than families with a daughter; the more interesting pattern is that families with a son in regions with a higher sex ratio tend to save more than their counterparts in regions with a lower sex ratio. This is true after taking into account the effects of other family and regional characteristics on the savings rate. In other words, it takes a combination of having a son at home and living in a region with an unbalanced sex ratio for parents to raise their savings rate.

At the province level, where one can compute the local aggregate savings rate in a way that is parallel to the national savings rate, the finding is that regions with a higher sex

ratio tend to have a higher aggregate savings rate. This means that the higher savings rates 
by families with a son are not offset by dis-savings of other households. In other words, in general equilibrium, a higher sex ratio is associated with a higher savings rate.

To go from correlation to causality, Wei and Zhang (2011a) use regional variations in the enforcement of the family planning policy as instruments for the local sex ratio. The idea is that a harsher penalty for violating birth quotas is likely to induce families to engage in more aggressive sex selective abortions, leading to a more unbalanced sex ratio. Their first stage regression confirms that this is indeed the case. The instrumental variable (IV) regressions confirm a positive effect of a higher sex ratio on the savings rate. Based on the IV regressions, they estimate that the observed rise in the sex ratio may explain about $50-60 \%$ of the observed rise in the household savings rate in China.

Interestingly, there is some evidence that a substantial part of the increase in Chinese corporate savings may also come from the sex ratio imbalance. First, Bayoumi, Tong, and Wei (2012) present evidence that private-owned firms tend to have a higher savings rate than state-owned firms (since the private firms cannot rely on banks or the capital market to raise funds). Second, Wei and Zhang (2011b) show that a higher sex ratio has substantially stimulated private entrepreneurship - entrepreneurship is viewed as another way to raise the family wealth and hence to enhance one's status in the marriage market. The increase in the sex ratio during 1995-2004 is estimated to explain about $20 \%$ of the increase in the number of private firms in urban areas, and about $40 \%$ of the increase in the number of private firms in rural areas. Since private firms outnumber state-owned firms by a large margin, savings by private firms are an important part of the overall corporate savings. Therefore, a rise in the sex ratio may have raised both the corporate savings rate and the household savings rate.

\subsection{Micro-level evidence on effective labor supply}

Some evidence that a higher sex ratio has increased effective labor supply is provided in Wei and Zhang (2011b). In particular, based on a survey of rural households, they examine whether/how a household's supply of labor as a migrant worker is affected by the local sex ratio. (Because of the government restrictions on formal migration from a rural area to a city, most migrant workers' time in a city are temporary. Their children typically cannot go to local schools or enjoy local health benefits. As a result, being a migrant worker involves a lot of sacrifice associated with being away from the family on an extended period of time.) Our theory would predict that a combination of having a son at home and living in a region with a higher male/female ratio would raise the willingness for a household to supply more labor. We cite their Tobit estimation results in our Table 1 . The evidence is consistent with this prediction. In the first column, we look at households with a son. The coefficient on the local sex ratio is positive and statistically significant. An increase in the sex ratio by 0.10 is associated with an increase in the supply of off farm labor by 2 days/year $(=20.8 \times 0.10)$. In 
the second column, we look at households with a daughter. The coefficient on the sex ratio is not statistically significant, which implies that the supply of off-farm labor by daughter families is uncorrelated with the sex ratio. In the third column, Wei and Zhang (2011b) combine the two sets of households, and add a dummy for son families and an interaction term between the dummy and the sex ratio. We can see that only the interaction term is positive and statistically significant. In other words, a combination of having a son and living in a region with a high sex ratio motivates these households to be more willing to work away from home. They also check if the supply of labor in response to a higher sex ratio varies by the income level of households. The last three columns show that there is no statistical difference across income groups.

Wei and Zhang (2011b) also examine another dimension of effective labor supply: willingness to accept intrinsically unpleasant or dangerous jobs. Such jobs are defined as those in mining or construction, or with exposure to extreme heat, cold, or hazardous material. People accept such a job presumably for a better wage. Our theory would again suggest that a combination of having an unmarried son at home and living in a region with a higher male/female ratio would motivate people to be more willing to accept such jobs. The empirical patterns (from a Probit regression) are indeed consistent with this prediction.

Interestingly, while some parents with a daughter also work as migrant workers and/or accept jobs that are intrinsically unpleasant or dangerous, their supply of work effort is uncorrelated with the local sex ratio. In other words, if a higher sex ratio produces incentives for parents with a daughter to reduce their work effort, it is likely to have been offset by opposing incentives (such as a desire to protect their daughter's bargaining power within a marriage). Whatever the exact mechanism, Wei and Zhang (2011b) do not find evidence that the labor supply by parents with a daughter declines with a higher sex ratio (while the parents with a son do supply more labor). Overall, a higher sex ratio appears to lead to a net increase in the labor supply.

\subsection{Within-country evidence on the sex ratio and the real exchange rate}

One place to check the validity of our hypothesis is to examine regional variations in the real exchange rate (or the relative price of non-tradables) within a geographically large country. In this sub-section, we explore regional variations in China. An important advantage of a within-country study is that cultural norms, legal institutions, social security systems, and other factors can more plausibly be held constant across regions within a country than across countries. A potential disadvantage is that the regional sex ratio might not adequately capture the relative tightness of the local marriage market. Fortunately, for China, Wei and Zhang (2011a) provide evidence that the marriage market is still very local - over $90 \%$ of marriages take place between a man and a woman from the same rural county 
or the same city. Mobility for marriage purposes is relatively low. (Migrant workers tend to go back to their home county to get married, or go out to work after getting married.)

We run regressions of the following type:

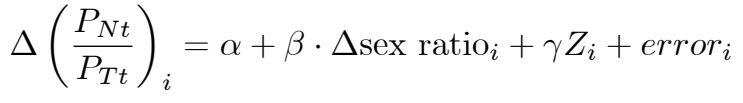

where the dependent variable is the cumulative change in the log price of the non-tradable sector relative to that of the tradable for province $i$ from 2001 to 2005, the first regressor is the cumulative change in the sex ratio for the same province over the same period, and $Z_{i}$ is a set of control variables. $\alpha, \beta$, and $\gamma$ are parameters to be estimated.

We obtain data on price indices (and their sub-indices) for 31 provinces over 20012005 from the China Statistics Yearbook database. The broad sectors are Food, Tobacco \& Liquor, Clothing, Household Facilities \& Services, Health, Transportation \& Communication, Recreation \& Education \& Culture, and Residence. We construct two measures of the changes in the relative price of non-tradable goods. For the first measure, we define five broad sectors (Household Facilities and Services, Health, Transportation \& Communication, Recreation \& Education \& Culture, and Residence) as non-tradables, ${ }^{12}$ and the rest as tradables. This breakdown follows the standard practice in the empirical international finance literature.

However, some of the broad non-tradable sectors may have sizable tradable components. As a refinement, we also construct a second measure of the relative price of the non-tradable by taking a more conservative approach that excludes plausibly tradable subcomponents from otherwise non-tradable broad sectors. More precisely, for the non-tradable basket, we only include the subsectors of Health, Transportation \& Communication, Household Services under the broad sector of Household Facilities and Services, the subsector of Recreation \& Culture Services under the broad sector of Recreation \& Education \& Culture, and the subsector of House Renting \& Utility under the broad sector of Residence. ${ }^{13}$

\footnotetext{
${ }^{12}$ In the literature, there is disagreement on whether the transportation and communication sector should be classified as tradable or non-tradable. De Gregorio, Giovannini, and Wolf (1994) classify this sector as tradable, while Burstein, Neves, and Rebelo (2003) and Burstein, Eichenbaum, and Rebelo (2005) consider transportation as non-tradable services. In this paper, we use the CPI data in China to compute the relative importance of the non-tradable part in the Transportation \& Communication sector. Data shows that the Transportation \& Communication sector includes the following sub-sectors: transportation facility, fuels and parts, using and upkeep service, within city traffic fare, inter-city traffic fare, communication facility and communication services. As in Burstein, Neves, and Rebelo (2003) and Burstein, Eichenbaum, and Rebelo (2005), we consider transportation services as non-tradable while transportation facility and fuels are considered as tradables. Similarly, we consider communication services as non-tradable while communication facility is tradable. Using CPI data, we estimate the weight of those sub-sectors in the transportation and communication sector, and find that the tradable part represents only $28 \%$ while the non-tradable part represents around $72 \%$. Hence, we classify the transportation and communication sector as non-tradable.

${ }^{13} \mathrm{As}$ in the literature, we classify all service goods as non-tradables and all commodity goods as tradables. There is no agreement as to whether the transportation and communication sector is tradable or non-tradable. In China, the transportation and communication sector includes the following sub-sectors:
} 
While some of the choices are judgment calls, the goal is to check if the basic relationship between the local relative price and the local sex ratio is robust to some perturbations of the definition of the relative price.

Somewhat inconveniently, instead of reporting the raw values of the price indices, the data source (China Statistics Yearbook) reports only annual changes of the indices with a potentially changing base from year to year. We accumulate the changes in the price indexes from 2001 to 2005. Because the data source does not report the weights assigned to various sub-indices in the CPI basket, we back out the weights by running an OLS regression of the changes in the overall CPI index on the changes in the sub-indices without an intercept.

The summary statistics on province-level variables - changes in the relative price of non-tradables from 2001 to 2005, measured in two ways as described above, and changes in the local sex ratio (which come from Wei and Zhang, 2011a), and some other variables - are reported in Table 2. During the period, the relative price of the non-tradable good by the first measure dropped by $6.0 \%$ on average. With a standard deviation of $4.3 \%$, there are substantial variations across different provinces. By the second measure, the relative price of non-tradable goods declined by $1.8 \%$ on average. With a standard deviation of $6.2 \%$, the coefficient of variations (or the ratio of standard deviation to mean) is even bigger for the second measure.

The sex ratio for the pre-marital age cohort during the same period rose by 2.1 basis points (or an increase in the sex ratio from 1079 young men per 1000 young women to 1100 young men per 1000 young women). With a standard deviation of 3.3\%, there are substantial variations across provinces in terms of the changes in the local sex ratio. These variations are useful for econometric identifications.

Table 3 reports the regression results. In Column 1, we regress the cumulative change in the relative price of non-tradables (first measure) on the cumulative change in the sex ratio (and an intercept). The coefficient of the sex ratio is negative and statistically significant. This implies that within China, regions with a faster relative increase in the sex ratio tend to exhibit a faster relative decline in the real exchange rate, which is consistent with our theory.

A well-known result in empirical international finance is that the real exchange rate tends to be systematically lower in poorer countries (or regions). A common explanation for this pattern is the Balassa-Samuelson theory. Separately, another demographic feature the age structure of the population - is often used to capture the life-cycle hypothesis on a country's savings behavior. In Column 2, we add both the change in local per capita income

transportation facility, fuels and parts, using and upkeep service, within city traffic fare, inter-city traffic fare, communication facility and communication services. We consider transportation facility, fuels and parts and communication facility as tradables and the rest as non-tradables. Using CPI data, we estimate the weight of those sub-sectors in the transportation and communication sector, and find that the tradable part represents only $28 \%$ while the non-tradable part represents around $72 \%$. Hence, we classify the transportation and communication sector as non-tradable. 
and the change in the share of working-age people in the local population as controls. These two variables turn out to be insignificant. In any case, the coefficient of the sex ratio remains negative and significant.

In Columns 3 and 4 of Table 3, we perform a simple robustness check by using the second measure of the relative price of non-tradables where the definition of a "non-tradable" is somewhat stricter. The results are qualitatively the same. In particular, the coefficients of the sex ratio are negative and statistically significant. In other words, regions with higher sex ratios tend to have lower values of the real exchange rate.

Because we are not aware of any other theory that predicts a negative association between the sex ratio and the real exchange rate, we find the patterns in Table 3 interesting. Nonetheless, there are other control variables one could think of such as regional financial development. Unfortunately, we do not have reliable data on these variables. We will next turn to some international evidence for which we could consider additional control variables.

\subsection{Cross-country evidence on the exchange rate}

We now provide some suggestive cross-country evidence on how the sex ratio imbalance may affect the real exchange rate. We first run regressions based on the following specification:

$$
\ln R E R_{i}=\alpha+\beta \cdot \operatorname{sex} \operatorname{ratio}_{i}+\gamma \cdot Z_{i}+\varepsilon_{i}
$$

where $R E R_{i}$ is the real exchange rate for country $i . Z_{i}$ is the set of control variables. We consider a sequentially expanding list of control variables including log GDP per capita, financial development index, government fiscal deficit, dependence ratio, and de facto exchange rate regime classifications.

The data for the real exchange rate and real GDP per capita are obtained from Penn World Table 7. The "price level of GDP" in the Penn World Table is equivalent to the real exchange rate in the model: A lower value of the "price level of GDP" means a lower value of the real exchange rate. The sex ratio data is obtained from the World Factbook. As we are not able to find the sex ratio for the age cohort 10-25 for a large number of countries, we use age group 0-15 instead to maximize the country coverage.

We use two proxies for financial development. The first is the ratio of private credit to GDP, from the World Bank's WDI dataset. This is perhaps the most commonly used proxy in the standard literature. There is a clear outlier with this proxy: China has a very high level of bank credit, exceeding $100 \%$ of GDP. However, $80 \%$ of the bank loans go to state-owned firms, which are potentially less efficient than private firms (see Allen, Qian, and Qian, 2005). To deal with this problem, we modify the index by multiplying the credit to GDP ratio for China by 0.2 . Because this measure is far from being perfect, we also use a second measure, which is the level of financial system sophistication as perceived by a 
survey of business executives reported in the Global Competitiveness Report (GCR).

For exchange rate regimes, we use two de facto classifications. The first comes from Reinhart and Rogoff (2004), who classify all regimes into four groups: peg, crawling peg, managed floating, and free floating. The second classification comes from Levy-Yeyati and Sturzenegger (2003), who use three groups: fix, intermediate, and free float.

For the dependent variable, log RER, and most regressors where appropriate, we use their average values over the period 2004-2008. The averaging process is meant to smooth out business cycle fluctuations and other noises. The period 2004-2008 is chosen because it is relatively recent, and the data are available for a large number of countries. (We have also examined a single year, 2006, and obtained similar results).

Table 4 provides summary statistics for the key variables. The log RER ranges from -1.51 to 0.49 in the sample, with a mean of -0.52 and a standard deviation of 0.40 . The value of $\log$ RER for China indicates a substantial undervaluation on the order of $83 \%$ when compared to the simple criterion of purchasing power parity.

For the sex ratio of the age cohort $0-15$, both the mean and the median across countries are 1.04, and the standard deviation is 0.02 . For this age cohort, all countries in the sample have a sex ratio that is at least 1 . The sex ratio for most countries is between 1 and 1.07. Some countries have an abnormally high sex ratio due to sex-selective abortions at birth. Others develop an abnormally high sex ratio in the young adult cohort due to gender-biased immigration or emigration pattern. The following economies have a sex ratio that is 1.07 or higher.

\begin{tabular}{ll|ll}
\hline \hline Economy & Sex ratio & Economy & Sex ratio \\
\hline China & 1.13 & Macao & 1.07 \\
Albania & 1.12 & India & 1.07 \\
Armenia & 1.12 & Singapore & 1.07 \\
Korea & 1.11 & Nepal & 1.07 \\
Hong Kong & 1.10 & Tunisia & 1.07 \\
Portugal & 1.09 & Macedonia & 1.07 \\
Switzerland & 1.08 & Venezuela & 1.07 \\
Vietnam & 1.08 & Ireland & 1.07 \\
\hline \hline
\end{tabular}

They represent the most skewed sex ratios in the sample. China, by far, has the most unbalanced sex ratio in the world. If the same sex ratio persists into the marriage market, then at least one out of every nine young men cannot get married. As wives are typically a few years younger than their husbands, the actual probability of not being able to marry is likely to be modestly better in a country with a growing population (for which later cohorts are slightly larger). Nonetheless, the relative tightness of the marriage market for men across countries should still be highly correlated with this sex ratio measure. In addition, unlike most other countries, China exhibits a progressively smaller age cohort over time 
(for the population younger than 40) as a result of its strict family planning policy. As a result, the relative tightness of the marriage market for Chinese men when compared to their counterparts in other countries is likely to be worse than what is represented by this sex ratio. Furthermore, the Chinese sex ratios at birth in 1990 and 2005 are estimated to be 1.15 and 1.20, respectively (see Wei and Zhang, 2011a). This implies that the sex ratio for the pre-marital age cohort will likely worsen in the foreseeable future.

We present a series of regressions in Table 5. The first column shows that the real exchange rate tends to be lower in poorer countries. This is commonly interpreted as confirmation of the Balassa-Samuelson effect. In Column 2, we add a proxy for financial development using the ratio of private sector credit to GDP. The positive coefficient of the new regressor indicates that countries with a less developed financial system tend to have a lower RER. In Column 3, we add the sex ratio. The coefficient of the sex ratio is negative and statistically significant, indicating that countries with a higher sex ratio tend to have a lower RER.

Since oil exporting countries have a current income that is likely to be substantially higher than their permanent income (if their oil reserves have a finite life), their RER patterns may be different from those of other economies. In Column 4, we exclude major oil exporters and re-do the regression. This turns out to have little effect on the result. In particular, countries with a higher sex ratio continue to exhibit a lower RER.

In Column 5 of Table 5, we include several additional control variables: government fiscal deficit, terms of trade, capital account openness, and dependency ratio. Due to missing values for some of these variables, the sample size is dramatically smaller (a decline from 122 in Column 4 to 91 in Column 5). Of these variables, only the dependency ratio is statistically significant. The positive coefficient on the dependency ratio (0.009) means that countries with a low dependency ratio (fewer children and retirees as a share of the population) tend to have a low RER. By the logic of the life-cycle hypothesis, a lower dependency ratio produces a higher savings rate. By the model in Section 2, this could lead to a reduction in the value of the real exchange rate. It is noteworthy, however, that even with these additional controls and in a smaller sample, the sex ratio effect is still statistically significant, and its point estimate is only slightly smaller.

In Column 6 of Table 5, we take into account exchange rate regimes using the ReinhartRogoff (2004) de facto regime classification. Relative to the countries on a fixed exchange rate regime (the omitted group), those on a crawling peg appear to have a lower RER. Countries on other currency regimes do not appear to have a systematically different RER. With these controls, the negative effect of the sex ratio on the RER is still robust. In Column 7 , we measure exchange rate regimes by the de facto classification proposed by Levy-Yeyati and Sturzenegger (2003). It turns out that this does not affect the relationship between the sex ratio and the real exchange rate either. 
To be clear, as the sex ratio imbalance is a severe problem only in a subset of countries, it is not a key fundamental determinant for the real exchange rate in most countries. Nonetheless, for those countries with a severe sex ratio imbalance, including China, one may have an inaccurate view of the equilibrium exchange rate unless one takes it into account. To illustrate the quantitative significance of the empirical relations, we compute the extent of the Chinese real exchange rate undervaluation (or the value of the actual RER relative to what can be predicted based on the fundamentals) by taking the point estimates in Columns 1-2 and 5 of Table 5 , respectively, at their face value. The results are tabulated in Table 6 . As noted earlier, relative to the simple-minded PPP, the Chinese exchange rate is undervalued by about $83 \%$. Once we adjust for the Balassa-Samuelson effect, the extent of the undervaluation becomes $31 \%$ (column 1 of Table 6 ). If we additionally consider financial underdevelopment (proxied by the ratio of private sector loans to GDP), the Chinese RER undervaluation is reduced to $19 \%$ (column 2, row 1 of Table 6), which is still economically significant. If we also take into account government deficit, terms of trade, and capital account openness, the extent of the RER undervaluation becomes 23\% (column 3, row 1). If we further take into account the dependency ratio, the extent of undervaluation drops to $7 \%$ (column 4, row 1). Finally, if we add the sex ratio effect, not only can we eliminate the appearance of undervaluation, the Chinese real exchange rate appears to be overvalued by 15\% (column 5, row 1 of Table 6).

If we proxy financial development by the World Economic Forum's rating of financial system sophistication, and also take into account the sex ratio effect and other structural variables, the Chinese real exchange rate appears to be overvalued by $21 \%$ (column 5 , row 2 of Table 6 ). These calculations illustrate that the sex ratio is an economically important determinant of the real exchange rate, though not the only one. If one uses an exchange rate determination model that does not take into account the sex ratio effect, one tends to systematically mis-label countries with a higher-than-average sex ratio as having an undervalued real exchange rate.

\subsection{Cross-country evidence on savings}

In this section, we provide suggestive cross-country evidence that supports the competitive savings motive. We run regressions based on the following specification:

$$
\text { savings.rate }_{i}=\alpha+\beta \cdot \operatorname{sex} \operatorname{ratio}_{i}+\gamma \cdot Z_{i}+\varepsilon_{i}
$$

where $Z_{i}$ is the set of control variables. We consider a sequentially expanding list of control variables including log GDP per capita, financial development index, dependency ratio (a proxy for life-cycle theory), and social security expenditure to GDP ratio (a proxy for precautionary savings theory). 
Table 7 show the results. In each regression, we have a positive and statistically significant coefficient of the sex ratio: as the sex ratio becomes more unbalanced, the savings rate tends to go up. In all regressions, the coefficients of the sex ratio are greater than 110. This illustrates the magnitude of the estimates: a rise in the sex ratio from 1 to 1.10 is associated with an increase in the savings rate by more than 11 percent of GDP $(>110 \cdot 0.1=11)$.

We comment briefly on other control variables. In Table 7, we find that: i) the coefficients of income are all positive and four out of six are statistically significant, which implies that a higher income may be associated with a higher savings rate; ii) the financial development index (private credit as \% of GDP) sometimes has a negative and significant sign, and the negative sign is consistent with Caballero, Farhi, and Gourinchas (2008) and Ju and Wei (2010 and 2011); iii) a higher government deficit is associated with a lower savings rate and in four out of five regressions, those coefficients are statistically significant; iv) the dependency ratio is negative (consistent with the life-cycle theory) but statistically insignificant, which suggests that life cycle considerations may not play a strong role in explaining cross-country variations in the savings rate; v) the social security expenditure to GDP ratio is negative (consistent with the precautionary savings theory) but statistically insignificant. It is noteworthy that with additional controls and in a smaller sample, the sex ratio effect is still statistically significant (although all other variables have insignificant coefficients).

\subsection{Cross-country evidence on labor supply}

We also provide some suggestive evidence of how cross-country differences in sex ratios affect the actual hours worked per employee. We run a regression based on the following specification

$\ln ($ hours actually worked per employee $)=\alpha+\beta \cdot \operatorname{sex} \operatorname{ratio}_{i}+\gamma \cdot Z_{i}+$ error $_{i}$

Data for hours actually worked per employee can be obtained from the ILO database. $Z_{i}$ denotes a set of other control variables. Our theory predicts that, for men alone or for combined women and men, $\beta$ is positive. For women, it is ambiguous whether $\beta$ is positive or negative.

Table 8 reports the regression results. Note that the dependent variable is more about individual decisions on labor supply. Though macro variables such as the dependency ratio influence the aggregate labor supply in a country, they may have little impact on individual decisions and hence, we do not include them in the regressions. In the first three columns, we run regressions using the full sample. We can see that, as the sex ratio rises, labor supply by total women and men as well as labor supply by men goes up. The effect is 
also statistically significant. However, for women, even if we obtain a positive coefficient for the sex ratio, the effect is not statistically significant. In Columns (4) to (6), we drop one potential outlier (China) and re-run the regressions. We obtain similar results. Note that the coefficients of log GDP per capita are always negative and significant based on our regression results, which may suggest a standard wealth effect on labor supply.

\section{Conclusion}

This paper shows that competition for marriage partners can alter the equilibrium real exchange rate by affecting savings and labor supply. Since several economies have exhibited a surge in the sex ratio for the pre-marital cohort in recent years, this factor may have risen in importance.

Standard models used to assess equilibrium exchange rates do not take into account the sex ratio imbalance. We show that a dramatic rise in the sex ratio for the pre-marital age cohort in China since 2003 could logically generate a decline in the equilibrium value of the real exchange rate. If other factors have also contributed to a rise in the Chinese household savings rate, such as a reduction in the dependency ratio, or a rise in the corporate and government savings rates, they can complement the sex ratio effect and reinforce an appearance of an undervalued currency even when there is no manipulation. To be clear, this paper does not make a judgement on whether a policy-induced undervaluation occurs in any particular country. Instead, it illustrates potential pitfalls in assessing the equilibrium exchange rate when important structural factors are not accounted for.

Empirically, countries with a higher sex ratio do appear to have a lower value of the real exchange rate. If we take the econometric point estimates at face value, one can account for virtually all of the departure of the Chinese real exchange rate from the purchasing power parity by the sex ratio effect and other structural factors.

In future research, the model could be extended to allow for endogenous adjustment of the sex ratio. (Data suggests that such an adjustment is slow, as most countries that have a sex ratio imbalance continue to exhibit a deterioration over time.) This is not easy to do technically, but will help us to assess the speed of the reversal of the sex ratio and the unwinding of the currency "undervaluation." We encourage more research on this topic.

\section{References}

[1] Allen, Franklin, Jun Qian, and Meijun Qian, 2005, "Law, Finance, and Economic Growth in China," Journal of Financial Economics, 77(1): 57-116. 
[2] Bayoumi, Tamim, Hui Tong, and Shang-Jin Wei, 2012, "The Chinese Corporate Savings Puzzle: A Firm-Level Cross-Country Perspective," Chapter 6 in Joseph P.H. Fan and Randall Morck (eds.), Capitalizing China, Chicago and London: University of Chicago Press.

[3] Bhaskar, V., 2011, "Parental Sex Selection and Gender Balance," American Economic Journal: Microeconomics, 3(1): 214-244.

[4] Bhaskar, V., and Ed Hopkins, 2011, "Marriage as a Rat Race: Noisy Pre-Marital Investments with Assortative Matching," Unpublished working paper, University College London and University of Edinburgh.

[5] Blanchflower, D.G., and A.J. Oswald, 2004, "Well-being over time in Britain and the USA," Journal of Public Economics 88 (7-8): 1359-1386.

[6] Browning, M., F. Bourguignon, P.-A. Chiappori, and V. Lechene, 1994, "Income and Outcomes: A Structural Model of Intrahousehold Allocation," Journal of Political Economy, 102(6): 1067-1096.

[7] Browning, M. and P.-A. Chiappori, 1998, "Efficient Intra-household Allocations: A General Characterization and Empirical Tests," Econometrica, 66(6): 1241-1278.

[8] Burstein, Ariel, Martin Eichenbaum and Sergio Rebelo, 2005, "Large Devaluations and the Real Exchange Rate," Journal of Political Economy, 113(4): 742-784.

[9] Burstein, Ariel, Joao Neves, and Sergio Rebelo, 2003, "Distribution Costs and Real Exchange-Rate Dynamics During Exchange-Rate-Based Stabilizations," Journal of Monetary Economics, 50(6): 1189-1214.

[10] Caballero, Ricardo, Emmanuel Farhi, and Pierre-Olivier Gourinchas, 2008, "An Equilibrium Model of 'Global Imbalances' and Low Interest Rates," American Economic Review, 98(1): 358-393.

[11] Chiappori, Pierre-André, 1988, "Rational Household Labor Supply," Econometrica, 56(1): 63-89.

[12] Chiappori, Pierre-André, 1992, "Collective Labor Supply and Welfare," Journal of Political Economy, 100(3): 437-467.

[13] Chinn, Menzie, 2012, Empirical Exchange Rate Economics: Estimation and Implications, Cambridge, MA: Cambridge University Press.

[14] Cole, Harold L., George J. Mailath, and Andrew Postlewaite, 1992, "Social Norms, Savings Behavior, and Growth," Journal of Political Economy, 100(6): 1092-1125. 
[15] Cooper, Russell W., and John Haltiwanger, 2006, "On the Nature of Capital Adjustment Costs," Review of Economic Studies, 73(3): 611-634.

[16] Corneo, Giancamo and Olivier Jeanne, 1999, "Social Organization in an Endogenous Growth Model," International Economic Review, 40(3): 711-725.

[17] De Gregorio, Jose, Alberto Giovannini, and Holger C. Wolf, 1994, "International evidence on tradables and nontradables inflation," European Economic Review, 38(6): $1225-1244$.

[18] Donni, Olivier, 2006, "The Intrahousehold Allocation of Private and Public Consumption: Theory and Evidence from U.S. Data," IZA DP no. 2137.

[19] Du, Qingyuan, and Shang-Jin Wei, 2013, "A theory of the competitive saving motive," Journal of International Economics, 91(2): 275-289.

[20] Gale, D., and L. S. Shapley, 1962, "College Admissions and the Stability of Marriage," American Mathematical Monthly, 69(1): 9-15.

[21] Gali, Jordi, J.D. López-Salido, and Javier Vallés, 2004, "Rule of Thumb Consumers and the Design of Interest Rate Rules," Journal of Money, Credit, and Banking, 36(4): 739-764.

[22] He, Hui, Ning Lei, and Dongming Zhu, 2014, "Rapid Aging and Pension Reform: The Case of China," Working paper, Shanghai University of Finance and Economics.

[23] Hopkins, Ed, 2009, "Job Market Signaling of Relative Position, or Becker Married to Spence," Working paper, University of Edinburgh.

[24] Hopkins, Ed, and Tatiana Kornienko, 2004, "Running to Keep in the Same Place: Consumer Choice as a Game of Status," American Economic Review, 94(4): 10851107 .

[25] Ju, Jiandong, and Shang-Jin Wei, 2010, "Domestic Institutions and the Bypass Effect of Financial Globalization," American Economic Journal: Economic Policy, 2(4): 173204.

[26] Ju, Jiandong, and Shang-Jin Wei, 2011, "When is Quality of Financial Sytem a Source of Comparative Advantage?," Journal of International Economics, 84(2): 178-187.

[27] Levy-Yeyati, Eduardo, and Federico Sturzenegger, 2003, "To Float or to Fix: Evidence on the Impact of Exchange Rate Regimes on Growth," American Economic Review, 93(4): 1173-1193. 
[28] Li, Hongbin, and Hui Zheng, 2009, "Ultrasonography and Sex Ratios in China," Asian Economic Policy Review, 4(1): 121-137.

[29] Obstfeld, Maurice and Kenneth Rogoff, 1996, Foundations of International Macroeconomics, Cambridge, MA: The MIT Press.

[30] Qian, Nancy, 2008, "Missing Women and the Price of Tea in China: The Effect of Sexspecific Earnings on Sex Imbalance," Quarterly Journal of Economics, 123(3): 12511285 .

[31] Reinhart, Carmen, and Kenneth Rogoff, 2004, "The Modern History of Exchange Rate Arrangements: A Reinterpretation," Quarterly Journal of Economics, 119(1): 1-48.

[32] Sarno, Lucio, and Mark P. Taylor, 2002, The Economics of Exchange Rates, Cambridge, MA: Cambridge University Press.

[33] Song, Zheng, Kjetil Storesletten, and Fabrizio Zilibotti, 2011, "Growing Like China," American Economic Review, 101(1): 196-233.

[34] Song, Zheng, Kjetil Storesletten, Yikai Wang, and Fabrizio Zilibotti, 2015, "Sharing High Growth across Generations: Pensions and Demographic Transition in China," American Economic Journal: Macroeconomics, 7(2): 1-39.

[35] Song, M., and D. Yang, 2010, "Life Cycle Earnings and the Household Saving Puzzle in a Fast-Growing Economy," Working paper, Chinese University of Hong Kong.

[36] Stockman, Alan C. and Linda L. Tesar, 1990, "Tastes and Technology in a Two-Country Model of the Business Cycle: Explaining International Co-Movements," National Bureau of Economic Research, Working Paper No. 3566.

[37] Wei, Shang-Jin, and Xiaobo Zhang, 2011a, "The Competitive Saving Motive: Evidence from Rising Sex Ratios and Savings Rates in China," Journal of Political Economy 119(3): 511-564.

[38] Wei, Shang-Jin, and Xiaobo Zhang, 2011b, "Sex Ratios, Entrepreneurship, and Economic Growth in the People's Republic of China," National Bureau of Economic Research, Working Paper No. 16800.

[39] Wu, Guiying Laura, 2011, "Aggregate Output Loss in China: An Indirect Inference from Capital Adjustment Costs," Working paper, Nanyang Technological University. 